\title{
Modulatory Effects of Cilostazol; an Nrf2/HO-1 activator against NAFLD in Rats Confirmed by Molecular Docking and FTIR Studies
}

Ahmed A.Sedik ( $\square$ aa.sedik@gmail.com )

National Research centre

Asmaa A.Amer

National Research centre

\section{Research Article}

Keywords: NAFLD, Cilostazol, FTIR, Nrf2/HO-1, anti-hyperlipdemic, anti-inflammatory

Posted Date: February 14th, 2022

DOI: https://doi.org/10.21203/rs.3.rs-1328467/v2

License: (c) (i) This work is licensed under a Creative Commons Attribution 4.0 International License.

Read Full License 
Modulatory Effects of Cilostazol; an Nrf2/HO-1 activator against NAFLD in Rats Confirmed by Molecular Docking and FTIR Studies

\author{
Ahmed A. Sedik ${ }^{1 *}$, Asmaa A. Amer ${ }^{2}$ \\ I*Department of Pharmacology, Medical Research and Clinical Studies Institute, National \\ Research Center, National Research Centre, Dokki, 12622, Cairo, Egypt \\ ${ }^{2}$ Department of Pharmacognosy Pharmaceutical and Drug Industries Research Institute, National \\ Research Centre, Dokki, 12622, Cairo, Egypt
}

Corresponding author: Ahmed A. Sedik

E-mail: aa.sedik@gmail.com

Tel: +201271667899. 


\begin{abstract}
Nonalcoholic fatty liver disease (NAFLD) is a complex hepato-metabolic syndrome with multi-etiological pathways. No effective drugs have been settled for the effective therapy of NAFLD. The purpose of this study was to investigate the modulatory effects of cilostazol (CILO, 50 and $100 \mathrm{mg} / \mathrm{kg}$.p.o.) against NAFLD induced by high fat diet rich in cholesterol (HFD- CH) for 10 weeks. Thirty male Sprague dawely rats were divided into 4 groups (8 rat / group). Normal control group supplied with normal chow diet. Control positive group received high fat diet rich in cholesterol for 10 weeks. In addition, two CILO groups received (CILO, 50 and 100 $\mathrm{mg} / \mathrm{kg}$.p.o.). Oral administration of (CILO; $100 \mathrm{mg} / \mathrm{kg}$ ) showed promising results in reducing fasting glucose and insulin levels. Moreover, CILO could reduce the elevated hepatic lipids, oxidative stress biomarkers and inflammatory cytokines. In addition, CILO succeeded to restore the total protein levels and activate nuclear factor erythroid-related factor $2 /$ heme oxygenase-1 (Nrf2/HO-1) activity. Furthermore, administration of CILO for NAFLD rats succeeded to show corrected and normalized FTIR spectra. We also investigated the plausible binding interactions of CILO with various biological targets using a molecular docking approach, and the results showed that CILO had an excellent docking energy score and significant binding interactions with the core amino acids involved in the active pocket for the enzymes studied. This study depicts that CILO exerted new intervention for NAFLD due to its complementary antihyperlipdemic, anti-inflammatory effects and antioxidant potential, via Nrf2/HO-1 activation.
\end{abstract}

Keywords: NAFLD, Cilostazol, FTIR, Nrf2/HO-1, anti-hyperlipdemic, anti-inflammatory.

\title{
1. Introduction
}

Nonalcoholic fatty liver disease (NAFLD) has a dramatically rising incidence in the western world and its prevalence continues to increase as a health crisis in society because hepatic lipid accumulation can trigger hepatocyte damage, inflammation and fibrogenesis (1). NAFLD is strongly associated with the risk of more severe conditions such as atherosclerosis 
and cardiovascular diseases (2). Liver is the chief modulator of the biological pathways associated with the mechanism of cholesterol metabolism, cholesterol synthesis, uptake from chylomicron remnants, re-uptake from high-density lipoproteins (HDL) as well as the release of cholesterol under very-low density lipoproteins (VLDL), and biliary acids production. All of these pathways have a dominant effect on the regulation of the concentrations of plasma cholesterol and subsequently increasing the lipoprotein triglyceride (TGs) - particles in the blood, leading to fatty disposition in the peripheral tissues and liver. Inflammation and oxidative stress are most crucial precipitating factors associated with liver injury (3).

NAFLD induced by high fat diet rich in cholesterol (HFD-CH) was related primarily to an oxidative injury and inflammation (4). Under normal and oxidative conditions, regulation of redox hemostasis occurs chiefly at the nucleus, and the nuclear factor erythroid-related factor2 (Nrf2) / hemoxygenase-1 (HO-1) signaling pathway is an important mediator for modulation of such responses (5). The impairment in the cellular redox homeostasis causes deviation in the level of inflammatory mediators such as nuclear factor kappa-b (NF- $\kappa \mathrm{B})$ and tumor necrosis factor (TNF- $\alpha$ ) which are required for repairing and regeneration of hepatocytes (6). Therefore, to avoid harmful oxidative conditions and to restore the redox homeostasis, activation of (Nrf2/HO-1) must being achieved (7). Hepatic injury is a detrimental factor for the severity of NAFLD. Several experimental and clinical attempts have been postulated for the therapy of the NAFLD, but none have shown prominent results on liver biomarkers and hepatic regeneration (8). Thus, urgent necessities for discovering safe therapeutic agents that can alleviate the precipitating factors and could reduce the hepatic accumulation of fats surrounding the liver are being mandatory.

Cilostazol (CILO) represents an attractive area in research due to its significant results in reducing reactive oxygen species (ROS) by acting as a non-enzymatic antioxidant (9). CILO is a quinolone derivative approved from FDA to treat intermittent claudication due to peripheral vascular disease (10). It was also used principally for the management of thrombotic diseases due to its anti-platelet activates. It also inhibits apoptosis and inflammatory changes in different models via decreasing the production of intracellular ROS (11).

Molecular Docking is a theoretical technique for studying protein-ligand interactions and recognition. Small molecule ligands are analysed in their interactions with receptor bio- 
macromolecules to find out how well they bind and how strong their affinity is, and then these interactions are used to develop structure-based drug design, which can be used to study molecular mechanisms of pharmacological effects, predict the structure of protein or ligandligand complexes, and allow targeted drug discovery to occur (12). The Increasing of computing and improving insights from computational chemistry approaches, the transformational influence of application of machine learning models to chemical sciences (13) .

Therefore, this study was conducted to evaluate the possible modulatory effects of cilostazol against metabolic, biochemical and molecular alterations induced by high fat diet rich in cholesterol (HFD- $\mathrm{CH}$ ) that mimics the pathophysiological features of NAFLD in human depending on Nrf2/HO-1 activation and its anti-inflammatory properties. Molecular docking studies help to predict the best active potential compounds against NAFLD proteins.

\section{METHODS}

\subsection{Experimental Animals}

Male Sprague dewily rats weighing 120-150 g were used throughout the study. Rats were acclimatized to optimal environmental laboratory conditions provided by the animal research colony (National Research Centre, Cairo, Egypt). Rats were provided with standard laboratory diet ad libitum with free access to water. The study was conducted in accordance with the ethical standards approved by the Medical Research Ethics Committee (MREC) of the National Research Centre, Dokki, Egypt (No.13111).

\subsection{Induction of NAFLD}

Induction of NAFLD in rats by daily administration of high fat diet rich in cholesterol (HFD-CH) composed of (55\% fat, $4 \%$ cholesterol powder, $20 \%$ carbohydrate and $21 \%$ protein, with equal quantities of minerals, vitamins and fibers (14). Cilostazol and cholesterol powder were purchased from sigma- Aldrich (USA).In addition, all other chemicals and kits were supplied from Randox.co, UK.

\subsection{Experimental design}

Thirty male sprague dawely rats, were divided into 4 groups (8 rat / group). Normal control group supplied with normal chow diet. Control positive group received high fat diet rich 
in cholesterol for 10 weeks. In addition to, two CILO groups received (CILO, 50 and 100 $\mathrm{mg} / \mathrm{kg}$.p.o.) for 2 weeks and continued for 8 weeks concurrent with high fat diet rich in cholesterol (15). At the end of the experiment, rats were fasted overnight and blood samples were collected from the retro-orbital plexus of ether-anesthetized animals and centrifuged $\left(800 \times \mathrm{g}, 4^{\circ} \mathrm{C}, 20 \mathrm{~min}\right)$ to separate serum that was analyzed for estimation of glucose and insulin levels.

Rats were sacrificed and liver tissues were excised, homogenized and divided into two parts. Part one is centrifuged at $4{ }^{\circ} \mathrm{C}(4000 \mathrm{rpm} / \mathrm{min}, 5 \mathrm{~min})$, and the supernatants were analyzed for determination of hepatic concentration of further biochemical indices. Part two is freeze dried and prepared for investigation of molecular alterations by the aid of fourier transform infrared (FTIR) spectroscopy.

\subsubsection{Anthropometric assessment}

Blood haemoglobin concentration and haematocrit values were measured using automated auto-analyzer (Mindray, UK). Mean corpuscular haemoglobin concentration $(\mathrm{MCHC})$ was then calculated as follows: Mean cell haemoglobin concentration $=\mathrm{Hb}(\mathrm{g} / 100$ $\mathrm{mL}) / \operatorname{Hct}(\%) \times 100$.

\subsubsection{Metabolic and biochemical assessment}

The concentration of fasting serum glucose was measured using glucose oxidase method, colorimetrically at $505 \mathrm{~nm}$ (16). Serum insulin level was determined by Enzyme Immunoassay (EIA) kit (17). Serum levels of aspartate aminotransferase (AST), alanine aminotransferase (ALT) were measured colorimetrically at $510 \mathrm{~nm}$ (18). Similarly, hepatic levels of total cholesterol (TC) and triglycerides (TG) were estimated at $505 \mathrm{~nm}$ using a calorimetric kit ((19, 20).

\subsubsection{Assessment of GSH and MDA levels in hepatic homogenate}

The hepatic concentration of reduced glutathione (GSH) was assessed depending on a colorimetric reaction where reduction of 5, 5-dithiobis-(2-nitrobenzoic acid) (DTNB) by SH group of glutathione occurs forming 2-nitro-S-mercaptobenzoic acid. The forming product was measured spectrophotometrically at $412 \mathrm{~nm}$ (21). In addition, the hepatic content of lipid peroxidation product, expressed as malondialdehyde (MDA) was determined through a 
reduction reaction occurs between one molecule of malondialdehyde with two molecules of 2thiobarbituricacid under optimal conditions at $\mathrm{pH}, 3.5$ ) forming pink coloured product that can be detected spectrophotometrically at $532 \mathrm{~nm}(\mathbf{2 2})$.

\subsubsection{Assessment of NO, SOD and HO-1 levels in hepatic homogenate}

Nitric oxide (NO) concentration was measured in liver homogenate via griess reaction, that involved in reduction of nitrate to nitrite, where with a mixture of naphthyl ethylene diamine and sulfanilamide was estimated spectrophotometrically at $540 \mathrm{~nm} \mathrm{(23).}$ Superoxide dismutase (SOD) activity was measured in liver homogenate at $420 \mathrm{~nm}$ by aspectrophotometer using colorimetric kit (24). Hepatic concentration of heme oxygenase-1 (HO-1) was measured spectrophotometry at $450 \mathrm{~nm}$ by using Eliza kit and HO-1 concentration was expressed as $\mathrm{ng} / \mathrm{mg}$ tissue (25).

\subsubsection{Analysis of fourier transform infrared spectroscopy (FTIR) spectra in hepatic tissue}

FTIR spectroscopy is a reliable and non-invasive tool capable of providing strong vision on the functional and structural alterations of macromolecules within tissue cell (26). Hepatic tissue samples were lyophilized for $24 \mathrm{~h}$. An equal and small amount of dried liver tissue samples were gently mixed with potassium bromide $(\mathrm{KBr})$ crystalls under a suitable pressure (1200 psi) for eight minutes to produce $\mathrm{KBr}$ pellets. In order to gain the same thickness of each pellet, samples were weighted and subjected to the same pressure. Pellets

were scanned at $4 \mathrm{~cm}-1$ within the mid-IR spectra $(3200-400 \mathrm{~cm}-1)$ at room temperature and the spectra was recorded using a Perkin Elmer Spectrum (Perkin Elmer Inc, USA) equipped with a DTGS detector (27).

\subsection{Statistical analysis}

All statistical comparisons were done using one-way analysis of variance (ANOVA) followed by Tukey's multiple comparison test, and the findings are expressed as mean SEM (8) rats. Graph Pad Prism v. 8.0 was used to examine the data (GraphPad Software, Inc., CA, USA). When the $\mathrm{p}$ value is less than 0.05 , the difference is considered significant.

\subsection{Computational analysis}


The crystal structure of target proteins were retrieved from the protein data bank at http://www.rscb.org./pdb using codes as illustrated in Table 1 (28-35). The water molecules were removed and the enzymes were prepared using QuickPrep tool module in MOE 2019.01 (Molecular Operating Environment, Version 2019.01, Chemical Computing Group Inc., Montreal, Canada), then active site was identified.

The chemical structure of CILO was obtained from PubChem (https://pubchem.ncbi.nlm.nih.gov/) as sdf files then loaded to MOE program. The structures were minimized using the MMFF94x force field until the RMSD of $0.01 \mathrm{kcal} \mathrm{mol}^{-1} \AA^{-1}$ was reached. The induced-fit protocol was used in the docking simulation, with the Triangle Matcher method used to place ligand conformations in the site, which were then ranked using the London $\Delta \mathrm{G}$ scoring function. The docking protocol was validated by running docking for the target protein's co-crystallized ligands. All the re-docked ligands had a low RMSD value less than $2 \AA^{-}$ 1 , indicating that the docking protocol was valid. One hundred docking poses were calculated, and the resulting docking poses were visualized using MOE 2019.01. The top-scored docking poses were used to calculate the binding free energy $(\Delta \mathrm{G})$ of CILO in $\mathrm{kcal} / \mathrm{mol}$.

\section{RESULTS}

\subsection{Effect of CILO on Blood Hg, Het and MCHC concentrations in NAFLD rats}

NAFLD in rats was induced by continuous daily consumption of HFD-CH for 10 weeks revealed no significant difference in the concentration of blood $\mathrm{Hg}$, Hct and $\mathrm{MCHC}$ compared with normal control rats. oral treatment of rats with CILO (50 and $100 \mathrm{mg} / \mathrm{kg}$ ) for 2 weeks and continued for 8 weeks concurrent with HFD-CH revealed also no significant difference in the concentration of blood $\mathrm{Hg}$, Hct and MCHC compared with control positive group (Table 2).

\subsection{Effect of CILO on the serum levels of glucose, insulin, total lipids and total proteins in NAFLD rats}

Adding high fat diet rich in cholesterol to rats for 10 consecutive weeks was associated with an increase in the levels of fasting serum glucose, insulin and total lipids reaching about $171 \%$, $147 \%$ and $149 \%$, respectively, compared with normal healthy rats. oral treatment of rats with CILO $(50 \mathrm{mg} / \mathrm{kg})$ for 2 weeks and continued for 8 weeks concurrent with HFD-CH was 
associated with a decrease in the levels of fasting serum glucose, insulin and total lipids reaching about $73 \%, 89 \%$, respectively. Administration of CILO $(100 \mathrm{mg} / \mathrm{kg})$ for NAFLD rats succeeded to restore the normal fasting glucose, insulin and total lipids levels (Figure 1).

Induction of NAFLD in rats by continuous daily consumption of HFD-CH for 10 weeks showed a decrease in total protein levels reaching about 75\%, compared with normal control group. oral treatment of rats with CILO $(50 \mathrm{mg} / \mathrm{kg})$ for 2 weeks and continued for 8 weeks concurrent with HFD-CH was associated with an increase in the levels of fasting serum total protein levels reaching about 121\%, respectively, compared with HFD-CH received rats. Administration of CILO $(100 \mathrm{mg} / \mathrm{kg})$ for NAFLD rats succeeded to restore the fasting normal total protein levels (Figure 2).

\subsection{Effect of CILO on serum AST, ALT, ALP levels and hepatic concentration of TGs and TC in NAFLD rats}

Adding HFD-CH for 10 consecutive weeks was associated with an increase in the levels of serum AST, ALT, ALP levels, hepatic concentration of TGs and TC reaching about 6 folds, 3 folds, 6 folds, $153 \%$ and 235\% respectively. oral treatment of rats with CILO (50 mg/kg) for 2 weeks and continued for 8 weeks concurrent with HFD-CH was associated with a decrease in the levels of serum AST, ALT, ALP levels, hepatic concentration of TGs reaching about 35\%, 50\%, $32 \%, 72 \%$, respectively and normalizing the levels of hepatic TC. Administration of CILO (100 $\mathrm{mg} / \mathrm{kg}$ ) for NAFLD rats succeeded to reduce the levels of serum AST, ALT, ALP levels, hepatic concentration of $\mathrm{TG}_{\mathrm{S}}$ reaching about $18 \%, 25 \%, 25 \%$, respectively and normalizing the levels of hepatic $\mathrm{TG}_{\mathrm{S}}$ and TC (Table 3).

\subsection{Effect of CILO on hepatic oxidative stress biomarkers in NAFLD rats}

NAFLD in rats was induced by continuous daily consumption of HFD-CH for 10 weeks revealed an increase in the concentration of hepatic MDA and NO reaching about 250\% and 5 folds . In addition, a decrease in hepatic GSH reaching about $36 \%$, compared with normal control rats. oral treatment of rats with CILO (50 and $100 \mathrm{mg} / \mathrm{kg}$ ) for 2 weeks and continued for

8 weeks concurrent with HFD-CH revealed a decrease in the concentration of hepatic MDA and NO reaching about $43 \%$ and $32 \%$. In addition, an increase in hepatic GSH reaching about $32 \%$, 
compared with control positive rats. Oral administration of CILO $(100 \mathrm{mg} / \mathrm{kg})$ for NAFLD rats succeeded to normalizing the levels of hepatic GSH, MDA and NO (Table 4).

\subsection{Effect of CILO on hepatic levels of pro- inflammatory cytokines in NAFLD rats}

Adding HFD-CH for 10 consecutive weeks was associated with an increase in the hepatic levels of TNF- $\alpha$ and NF- $\kappa \mathrm{B}$ reaching about $364 \%$ and 453\% respectively, compared with NAFLD group. oral treatment of rats with CILO $(50 \mathrm{mg} / \mathrm{kg})$ for 2 weeks and continued for 8 weeks concurrent with HFD-CH was associated with a decrease in the hepatic levels of TNF- $\alpha$ and NF- $\kappa \mathrm{B}$ reaching about $50 \%$ and $29 \%$, respectively, compared with control positive group. Administration of CILO (100 mg/kg) for NAFLD rats succeeded to normalize the hepatic levels of TNF- $\alpha$ and NF- $\kappa$ B (Table 5).

\subsection{Effect of CILO on hepatic levels of Nrf-2 expression and HO-1 levels in NAFLD rats}

Administration of HFD-CH for 10 consecutive weeks for was associated with a decrease in the hepatic levels of Nrf-2 expression and HO-1 reaching about $21 \%$ and $40 \%$ respectively, compared with NAFLD group. oral treatment of rats with CILO (50 mg/kg) for 2 weeks and

continued for 8 weeks concurrent with HFD-CH was associated with an increase in the hepatic levels of Nrf-2 expression and HO-1 reaching about $180 \%$ and normalization of HO-1 expression, respectively, compared with control positive group. Administration of CILO (100 $\mathrm{mg} / \mathrm{kg}$ ) for NAFLD rats succeeded to normalize the hepatic levels of Nrf-2 expression and HO-1 activity (Figure 3).

\subsection{Effect of CILO on hepatic molecular alterations in NAFLD rats}

Significant macromolecular bonding frequency regions are the characteristic features of the FT-IR spectra of hepatic specimens of HFD-CH. The most critical infrared absorbance bands are established between 1450 and $650 \mathrm{~cm} 1$, amide I and II region between 1700 and $1500 \mathrm{~cm} 1$, and $\mathrm{C}-\mathrm{H}$ stretching region between 3070 and $2800 \mathrm{~cm} 1$. The $\mathrm{C}-\mathrm{H}$ stretching region exhibits infrared bands of lipids with a small contribution from carbohydrates and proteins. The spectral bands 3012, 2957, 2923, and $2853 \mathrm{~cm} 1$ are attributed to $\mathrm{C} 1 / 4 \mathrm{CH}, \mathrm{CH} 3$ asymmetric, $\mathrm{CH} 2$ asymmetric, 
and $\mathrm{CH} 2$ symmetric stretch, respectively. Administration of CILO (100 mg/kg) for NAFLD rats succeeded to show corrected and normalized FTIR spectra (Figure 4).

\subsection{Molecular docking study using MOE}

Due to the current problems and intricate challenges faced by medicinal chemists, docking is a highly demanding and efficient discipline in order to rationally develop novel therapeutic compounds for treating human disease. In our study the potential of CILO as inhibitors for several biological targets including, peroxisome proliferator-activated receptor gamma (PPAR $\gamma)$, Peroxisome proliferator-activated receptor alpha (PPAR $\alpha$ ), heme oxygenase1 (HO1), transcription factor NF-E2-related factor 2 (Nrf2) tumor necrosis factor-alpha (TNF- $\alpha$ ), glutathione reductase, inducible nitric oxide synthase (iNOS) and catalase, was investigated using molecular docking technology. The binding affinity and interaction manners of the cilostazol with the selected enzymes were depicted in Table 1. At the commencement, the native ligand for each enzyme was re-docked into the active pocket to validate our docking methodology, and the results showed that all re-docked ligands had a comparable conformation to the native ligands, with RMSD values $\leq 2.0 \AA$.

CILO revealed lower binding energy of $-8.86 \mathrm{kcal} / \mathrm{mol}$ in the interaction with PPAR- $\gamma$ (PDB ID: 3K8S), compared to the native ligand, 2-chloro-N-\{3-chloro-4-[(5-chloro-1,3benzothiazol-2-yl)sulfanyl]phenyl \}-4-(trifluoromethyl)benzenesulfonamide (Z27) with a docking energy of $-9.94 \mathrm{kcal} / \mathrm{mol}$ (RMSD $1.94 \AA$ A, Table 1). Also, CILO showed excellent binding interaction with the PPAR- $\gamma$ active site via formation two H-bonds donor, one H-bond acceptor and Three pi-H interaction with the key amino acids MET 348, GLN 286 and CYS 285, HIS 449, respectively in comparison to $\mathbf{Z 2 7}$ which formed four H-bonds donor with MET 364 and CYS 285(Table 1, Figure 5a,b).

In the interaction with PPAR $\alpha$ (PDB ID: 3ET1, Table 1), cilostazol formed two H-bonds acceptor with the amino acid TYR 334 (Figure 6a,b) and exhibited strong docking score of $9.39 \mathrm{kcal} / \mathrm{mol}$ compared to the native ligand 3-\{5-methoxy-1-[(4-methoxyphenyl)sulfonyl]-1Hindol-3-yl \}propanoic acid (ET1) with score -10.36 kcal/mol (RMSD $1.24 \AA$ ). Furthermore, docking of cilostazol with the OH1 enzyme (PDB ID: 1DVE) led to the establishment of two Hbonds acceptor and Pi-cation interaction with ASP 140 and ARG 136, with a docking score of $8.06 \mathrm{kcal} / \mathrm{mol}$ (Table 1, Figure 7a,b) compared to the native ligand, protoporphyrin IX 
containing Fe (HEM) of $-11.82 \mathrm{kcal} / \mathrm{mol}$ (RMSD: $0.57 \AA$ ). While, in the interaction with Nrf2 (PDB ID: 5CGJ), cilostazol, demonstrated a strong binding energy of $-8.06 \mathrm{kcal} / \mathrm{mol}$, which was lower than (3S)-1-(4-\{[(2,3,5,6-tetramethylphenyl)sulfonyl $]$ amino $\}$ naphthalen-1-yl)pyrrolidine3-carboxylic acid (51M) of $-7.32 \mathrm{kcal} / \mathrm{mol}$ (RMSD: $2.6 \AA$ ) with the formation of two H-bonds acceptor with the core amino acid ARG 483 (Table 1, Figure 8a,b).

In the instance of tumor necrosis factor-alpha (TNF- $\alpha$; PDB ID: 2AZ5), CILO displayed good interaction with the enzyme active pocket by forming four $\mathrm{H}$-bonds donor and two pi-H interaction with the key amino acids GLY 121 and LEU 55 (Table 1, Figure 9a,b). Additionally, cilostazol had lower docking score of $-6.39 \mathrm{kcal} / \mathrm{mol}$, compared to native ligand, 6,7-dimethyl-3-[(methyl $\{2-[\operatorname{methyl}(\{1-[3-($ trifluoromethyl)phenyl]-1H-indol-3-yl $\}$ methyl) amino]ethyl amino)methyl]-4H-chromen-4-one (307) of $-7.74 \mathrm{kcal} / \mathrm{mol}$ (RMSD: $2 \AA$ ). On the other hand, docking of cilostazol with glutathione reductase (PDB ID: 1XAN) showed better docking energy of $-6.57 \mathrm{kcal} / \mathrm{mol}$ than co-crystalline ligand, 3,6-dihydroxy-xanthene-9-propionic acid (HXP) of $-5.26 \mathrm{kcal} / \mathrm{mol}$ (RMSD: $2.5 \AA$ ), with powerful interaction via formation of six $\mathrm{H}_{-}$ bond acceptors with SER 470 and HIS 82 (Table 1, Figure 10a,b).

Interestingly, CILO displayed docking score of $-7.60 \mathrm{kcal} / \mathrm{mol}$ with inducible nitric oxide synthase (PDB ID: 4CX7) which very comparable to score of the co-crystalline ligand S71 [(R)6-(3-amino-2-(5-(2-(6-amino-4-methylpyridin-2-yl)ethyl)pyridin-3-yl)propyl)-4-methylpyridin2-amine], $-7.95 \mathrm{kcal} / \mathrm{mol}$ and established a powerful interaction with the enzyme active pocket via formation of six $\mathrm{H}$-donor, seven $\mathrm{H}$-acceptor and five $\mathrm{Pi}-\mathrm{H}$ bonds with the core amino acids MET 355, CYS 200, TYR 491, SER 242, GLY 371 and GLY 202 (Table 1, Figure 11a,b).

Finally, CILO stabilized itself in the catalyase active pocket (PDB ID: 1TGU) through formation of three H-bonds acceptor and Three pi-pi interaction with ARG 364 and PHE 160 and showed binding energy of $-9.55 \mathrm{kcal} / \mathrm{mol}$ compared to co-crystalline ligand HEM of 14.85 and RMDS $0.46 \AA$ (Table 1, Figure 12a,b).

\section{Discussion}

NAFLD is a hepato-metabolic syndrome that is usually implicated in sever clinical and pathological disorders and is considered the major precipitating factors for insulin resistance, diabetes mellitus and cardiovascular diseases (36). NAFLD is asymptomatic hepatic manifestation that can progress to nonalcoholic steatohepatitis (NASH), hepatic fibrosis, 
cirrhosis, and hepatic cancer (37).Weight loss regimen and exercise are the only accepted treatments but are often a challengeable matter for NAFLD patients. Thus, there is an urgent necessity to explore safe agents for reducing the elevated hepatic lipids. According to the authors' knowledge, this is the primary study exploring the valuable role of Cilostazol, CILO; Nrf2/HO-1 activator against pathophysiological alterations induced by HFD- $\mathrm{CH}$ that parallel to NAFLD in human.

Our study showed that excessive consumption of HFD-CH for 10 weeks is a reliable and satisfactory model of NAFLD, showing typical symptoms of NAFLD including obesity, impaired glucose tolerance, hyperinsulinemea. In our study, HFD-CH was associated with increased glucose and insulin levels as a result of excess fat intake leads to hypertriglyceridemia and increased availability of free fatty acids that blunts the insulin-mediated decline in hepatic glucose output and decrease the glucose uptake or utilization in skeletal muscle leading to hyperinsulinemia (38). Oral treatment of NAFLD with CILO $(100 \mathrm{mg} / \mathrm{kg})$ treatment for 2 weeks and continued for 8 weeks was associated with normalizing serum glucose and insulin levels due to CILO relaxing systemic arterioles, which may increase blood flow through muscle tissue, thereby improving tissue response to glucose and insulin (39).

Previous study indicated that the metabolic functions of CILO as a blood glucose disposal through its direct role in cellular glucose uptake by regulating glucose metabolizing enzymes, prostaglandin dehydrogenase and alpha keto-glutarate dehydrogenase at the cellular membrane level (40). Its well- known that the lipid composition of the erythrocyte membrane (EM) is affected by long term dietary fatty intake leading to accumulation of cholesterol within EM, alteration in phospholipid :cholesterol ratio, increase in the rigidity of EM and eventually increase the osmotic fragility of erythrocytes (41). However, no significant difference in blood $\mathrm{Hg}$, Hct and MCHC concentrations, compared with control positive group.

The liver of rats fed HFD-CH is frequently associated with an extreme load of TGS, TC, and total lipids above the acceptable level, resulting in the liver's inability to metabolise free and bound lipids and a decrease in de novo synthesis of total proteins, resulting in a high concentration of TGS, TC, and total lipids in the free circulation and a decrease in total lipid concentration in the blood (42). In the present study, oral treatment of NAFLD with CILO (100 $\mathrm{mg} / \mathrm{kg}$ ) for 2 weeks, followed by 8 weeks of HFD-CH, was associated with normalization of 
TGS and TC hepatic concentrations (43). NAFLD may be responsible for the induction of cellular hepatic enzymes AST, ALT, and ALP, which are used to assess liver function. AST and ALT are intracellular enzymes that serve as a clinical indicator of tissue injury, particularly hepatocyte tissue injury (44). Elevated concentration of serum ALT, AST levels, and ALP activities in HFD-CH-treated rats was recorded showing structural membrane damage and releases of these enzymes into systemic circulation (45). Treatment of NAFLD with CILO (100 $\mathrm{mg} / \mathrm{kg}$ ) for 2 weeks followed by 8 weeks of HFD-CH resulted in normalization of serum hepatic enzymes, demonstrating that CILO preserves the hepatocellular membrane's structural integrity (46).

NAFLD has been accompanied with oxidative stress imbalance with general decrease in the efficiency of antioxidant system manifested with excessive generation of ROS levels, increased lipid peroxidation in hepatocytes and consequently impairment in the redox homeostasis causes alteration in pro-inflammatory cytokines (47). Our results revealed that HFD-CH received rats have reduced levels of hepatic GSH levels and increased levels of lipid peroxidation products (MDA) (48). Several biochemical pathways and mechanisms of action have been suggested, which relate the formation of ROS and NAFLD thus cause chronic oxidative stress. The findings of this study are in agreement with other investigations that reported a significant increase in lipid peroxidation and a significant decrease of hepatic antioxidant enzyme activities (49). In the present study, CILO could significantly modulate the balance between oxidants and antioxidants in the liver of HFD-CH received rats and leads to pronounced reduction in oxidative stress biomarkers and lipid peroxidation. CILO had beneficial effects on hepatic lipid peroxidation and restoring the activity of GSH enzyme which in turn decreased oxidative stress acting as antioxidant and scavenger of ROS (50). HFD-CH received rats was associated with an alteration in oxidative stress biomarkers due to exhaustion of glutathione that may debilitate cellular antioxidant defense to such appoint that NO synthesized by inducible NO synthase may cause hepatic injury (51). Our promising study revealed that CILO could normalize the hepatic content of NO and these results are in consistent with (52).

Hyperglycemia and elevated levels of free fatty acids and total lipids can triggers the release of proinflammatory cytokines and consequently hepatic inflammation as they are the driving forces for oxidative stress and ROS (53). In response to NAFLD, the initial induction of 
early inflammatory response potentiates the macrophage to produce cytokines mainly, TNF- $\alpha$ and NF- $\kappa \mathrm{B}$ (54). Specifically, TNF- $\alpha$ is involved in hepatic damage and is considered the critical sequels in different liver diseases (55). The finding of the present study showed that CILO could reduce the elevated levels of hepatic TNF- $\alpha$ and NF- $\kappa$ B. Our results are similar to a previous study reported that CILO could reduce the pro-inflammatory cytokines (TNF- $\alpha$ level) in common bile duct ligated rats (56). Moreover, CILO significantly reduced the level of lipopolysaccharides stimulated TNF- $\alpha$ mRNA and NF- $\mathrm{BB}$ from hepatocytes (57). Consequently, our study suggests that hepato-protective effects of CILO might be through mediating the suppression of the NF- $\kappa \mathrm{B}$ system in NAFLD rats (58).

Oxidative stress is regarded as one of the main precipitating factors associated with HFD-CH induced NAFLD. The transcription factor; Nrf2 protein participates effectively in triggering the induction of phase II detoxifying/antioxidant system to cope with oxidative stress through enhancing the expression of a number of enzymes (59). Regulation of redox balance under normal and oxidative stress conditions occurs primarily at the nuclear level, and the Nrf2/HO-1 is an essential mediator for such responses. Subsequently, the expression of several genes in response to these stressful conditions has been upregulated for the defense against a wide variety of diseases (60) . HO-1 is a highly inducible stress-related protein which enhances the rate-limiting step in heme degradation gives rise to biliverdin, carbon monoxide and free iron (11). Heme degradation products display antioxidant activity and vasodilation that can afford cytoprotection against oxidative stress (61). The present study showed that HFD-CH significantly reduced the expression levels of Nrf2 / HO-1 that were improved with CILO that exerted a preventive role on oxidative insults through targeting the Nrf2 / HO-1 induction and restoring the redox defense mechanisms (62).

FTIR spectroscopy was used to identify hepatotoxic and hepatoprotective effects of different chemicals and biochemical changes in the liver among various animal models (63). In the current study, molecular alterations were assessed using FTIR spectroscopy technique which monitors the vibration modes of functional groups present in proteins and lipids in liver tissue. FTIR spectra showed FTIR spectra in this range show a broad characteristic peak appears at $3284 \mathrm{~cm}-1$ which assigned as combination of $\mathrm{O}-\mathrm{H}$ and $\mathrm{N}-\mathrm{H}$ stretching vibration another important peak found at $2923 \mathrm{~cm}-1$ is attributed to the stretching vibration of $\mathrm{C}-\mathrm{H} 2$ group which represent the lipids structure (63). The peak at $1644 \mathrm{~cm}-1$ is a characteristic for N- 
$\mathrm{H}$ vibration (Amid I) which represents the protein structure. Paying particular attention to the range from $2923 \mathrm{~cm}-1$ to $3284 \mathrm{~cm}-1$ typical of $\mathrm{C}-\mathrm{H} 2$ stretching of lipids, and to the $\mathrm{O}-\mathrm{H}$ vibrational stretching region $1644 \mathrm{~cm}-1$ to $3284 \mathrm{~cm}-1$ revealing that the wave number of fatty acid species changed significantly in NAFLD, indicating the acyl chain modification of membrane lipids (64).

FTIR analysis of the $\mathrm{CH} 2, \mathrm{CH} 3$ stretching region $(3000-2800 \mathrm{~cm} 1)$ and ester carbonyl band at $1740 \mathrm{~cm} 1$ revealed the accumulation of lipids in NAFLD group (65). To determine the $\mathrm{CH} 2 / \mathrm{CH} 3$ ratio, a number of bands were fitted to the $\mathrm{CH}$ stretching region $(3000-2800 \mathrm{~cm} 1)$. The decrease in intensity of the $\mathrm{CH} 3$ stretching modes along with a concomitant increase in the $\mathrm{CH} 2$ stretching modes was indicative of oxidative processes occurring in response to NAFLD. The change in the $\mathrm{CH} 2 / \mathrm{CH} 3$ ratio is consistent with apoptosis (66). Oral treatment of rats received HFD-CH with CILO protected the hepatic molecular alterations due to its antioxidant and anti-lipid peroxidative potential in the liver via Nrf2/Ho-1 induction (67).

To the best of our knowledge, the current study is the first research for utilizing CILO biochemically and computationally as inhibitor for peroxisome proliferator-activated receptor gamma (PPAR $\gamma)$, Peroxisome proliferator-activated receptor alpha (PPAR $\alpha$ ), heme oxygenase-1 (HO-1), transcription factor NF-E2-related factor 2 (Nrf2) tumor necrosis factor-alpha (TNF- $\alpha$ ), glutathione reductase, inducible nitric oxide synthase (iNOS) and catalyase. The docking investigations were conducted using MOE 2019.01 (Molecular Operating Environment, Version 2019.01, Chemical Computing Group Inc., Montreal, Canada). The overall results indicated that CILO had excellent binding energy score and strong binding interactions with the core amino acids involved in the active pocket for the investigated enzymes (Table 1). It is worthy to mention that, the tetrazole ring, $\mathrm{NH}$ and $\mathrm{CO}$ groups in CILO structure played a significant role in the binding interaction with the target enzymes as shown in Table 1and Figures 6-12. Our docking result indicated that, CILO had lower binding energy of -8.86 $\mathrm{kcal} / \mathrm{mol}$ in the interaction with PPAR $\gamma$ (PDB ID: 3K8S) with the formation of three H-bonds and three pi-H interactions between NH group, tetrazole ring and MET 348, GLN 286, CYS 285, HIS 449 residues (Table 1, Figure 5a,b). While, molecular binding between CILO and PPAR $\alpha$ (PDB ID: 3ET1) active site have established two H-bonds acceptor between carbonyl group and TYR 334 residue with docking score of $-9.39 \mathrm{kcal} / \mathrm{mol}$ (Table 1, Figure 6a,b). On the other hand, binding energy of CILO with HO-1 enzyme (PDB ID: 1DVE) was $-8.06 \mathrm{kcal} / \mathrm{mol}$ and 
CILO - HO-1 complex was stabilized by establishment two H-bonds and Pi-cation interaction between tetrazole ring and ASP 140 and ARG 136 (Table 1, Figure 7a,b). Interaction of cilostazol with Nrf2 (PDB ID: 5CGJ) resulted in low binding energy of $-8.06 \mathrm{kcal} / \mathrm{mol}$, with good interaction with the active pockets through formation of two $\mathrm{H}$-bonds with the core amino acid ARG 483 and carbonyl group (Table 1, Figure 8a,b).

While, the complex produced by CILO and TNF- (PDB ID: 2AZ5) was stabilized by formation four $\mathrm{H}$-bonds and two pi-H interactions between the $\mathrm{NH}$ group, tetrazole ring and the essential amino acids GLY 121 and LEU 55 (Table 1, Figure 9a,b). Also, docking of CILO with glutathione reductase (PDB ID: $1 \mathrm{XAN}$ ) revealed lower docking energy of $-6.57 \mathrm{kcal} / \mathrm{mol}$, with robust contact via formation of six H-bonds between tetrazole ring, carbonyl group, and SER 470, HIS 82 residues (Table 1, Figure 10a,b). The complex produced between CILO and inducible nitric oxide synthase (PDB ID: 4CX7) was shown to have a strong binding interaction, with thirteen $\mathrm{H}$-bonds and five Pi-H bonds formed between the key amino acids MET 355, CYS 200, TYR 491, SER 242, GLY 371, GLY 202 and the NH, CO, cyclohexane, tetrazole rings (Table 1, Figure 11a,b).

Finally, docking of CILO with the catalase active pocket (PDB ID: 1TGU) demonstrated binding energy $-9.55 \mathrm{kcal} / \mathrm{mol}$ and established three $\mathrm{H}$-bonds and three pi-pi interaction with ARG 364 and PHE 160 (Table 1, Figure 12a,b).

\section{Conclusions}

Finally, we can conclude that the modulatory effect of cilostazol against nonalcoholic fatty liver disease induced by high fat diet rich may be attributed to its anti-hyperlipedemic activity, activation of Nrf2/HO-1 pathway, amelioration of oxidative stress, reducing the expression of pro-inflammatory cytokines. Thus, CILO may be a promising supplement to be used for patients with NAFLD in the future. In addition to molecular docking proved that CILO had strong binding interactions with the core amino acids involved in the active pocket for each investigated enzymes and excellent binding energy score.

\section{Declarations}

\section{Acknowledgments}


N/A

Funding

N/A

Availability of data and materials:

Available upon request

\section{Author information}

Affiliations

Ahmed A. Sedik Department of Pharmacology, Medical Research and Clinical Studies

Institute,National Research Centre, Dokki, 12622, Cairo, Egypt

Asmaa A. Amer Pharmacognosy Department, Pharmaceutical and Drug Industries Research

Institute, National Research Centre, Dokki, 12622, Cairo, Egypt

\section{Contributions}

Ahmed A.Sedik has designed and conducted the study. Asmaa A.Amer has conducted molecular docking studies. Authors had approved the final version of the article to be published.

\section{Corresponding author}

\section{Correspondence to Ahmed A. Sedik}

\section{Ethical Approval and consent to Participate}

The study was reviewed and approved by Medical Research Ethics Committee (MREC) of the National Research Centre (Egypt).

\section{Consent to Publish}

The author has read and approved the final manuscript. All authors read and approved the manuscript and all data were generated in-house and that no paper mill was used.

\section{Competing interests}

The author declare that no conflict of interests exist

\section{References}

1. Gupta A, Dhiman RK, Kumari S, Rana S, Agarwal R, Duseja A, et al. Role of small intestinal bacterial overgrowth and delayed gastrointestinal transit time in cirrhotic patients with minimal hepatic encephalopathy. 2010;53(5):849-55.

2. Targher GJDm. Non-alcoholic fatty liver disease, the metabolic syndrome and the risk of cardiovascular disease: the plot thickens. 2007;24(1):1-6.

3. Kanwar P, Nelson JE, Yates K, Kleiner DE, Unalp-Arida A, Kowdley KVJBog. Association between metabolic syndrome and liver histology among NAFLD patients without diabetes. 2016;3(1).

4. Al-Attar AM, Alrobai AA, Almalki DAJSjobs. Protective effect of olive and juniper leaves extracts on nephrotoxicity induced by thioacetamide in male mice. 2017;24(1):15-22.

5. Suzuki T, Yamamoto MJFRB, Medicine. Molecular basis of the Keap1-Nrf2 system. 2015;88:93100.

6. Connolly MK, Bedrosian AS, Clair JM-S, Mitchell AP, Ibrahim J, Stroud A, et al. In liver fibrosis, dendritic cells govern hepatic inflammation in mice via TNF- $\alpha .2009 ; 119(11): 3213-25$.

7. David JA, Rifkin WJ, Rabbani PS, Ceradini DJJJodr. The Nrf2/Keap1/ARE pathway and oxidative stress as a therapeutic target in type II diabetes mellitus. 2017;2017.

8. Hernández A, Arab JP, Reyes D, Lapitz A, Moshage H, Bañales JM, et al. Extracellular Vesicles in NAFLD/ALD: From Pathobiology to Therapy. 2020;9(4):817. 
9. Elam M, Heckman J, Crouse J, Hunninghake D, Herd J, Davidson M, et al. Effect of the novel antiplatelet agent cilostazol on plasma lipoproteins in patients with intermittent claudication. 1998;18(12):1942-7.

10. Balinski AM, Preuss CV. Cilostazol. 2019.

11. Chen Y, Pandiri I, Joe Y, Kim HJ, Kim S-K, Park J, et al. Synergistic effects of cilostazol and probucol on ER stress-induced hepatic steatosis via heme oxygenase-1-dependent activation of mitochondrial biogenesis. 2016;2016.

12. Nazar MF, Abdullah MI, Badshah A, Mahmood A, Rana UA, Khan SU-D. Synthesis, structureactivity relationship and molecular docking of cyclohexenone based analogous as potent non-nucleoside reverse-transcriptase inhibitors. Journal of Molecular Structure. 2015;1086:8-16.

13. Ahmad F, Mahmood A, Muhmood T. Machine learning-integrated omics for the risk and safety assessment of nanomaterials. Biomaterials science. 2021.

14. Ramadan AA, Afifi NA, Erian EY, Saleh DO, Sedik AAJWJPPS. Beneficial effect of trigonelline on the metabolic changes associated with insulin resistance in rats. 2015;5(2):1238-50.

15. El Awdan SA, Abdel Rahman RF, Ibrahim HM, Hegazy RR, El Marasy SA, Badawi M, et al. Regression of fibrosis by cilostazol in a rat model of thioacetamide-induced liver fibrosis: Up regulation of hepatic CAMP, and modulation of inflammatory, oxidative stress and apoptotic biomarkers. 2019;14(5):e0216301.

16. Trinder PJJocp. Determination of blood glucose using an oxidase-peroxidase system with a noncarcinogenic chromogen. 1969;22(2):158-61.

17. Grassi J, Roberge CJ, Frobert Y, Pradelles P, Poubelle PEJIr. Determination of ILl $\alpha$, ILI $\beta$ and IL2 in Biological Media using Specific Enzyme Immunometric Assays. 1991;119(1):125-45.

18. Reitman S, Frankel SJAjocp. A colorimetric method for the determination of serum glutamic oxalacetic and glutamic pyruvic transaminases. 1957;28(1):56-63.

19. Richmond WJCc. Preparation and properties of a cholesterol oxidase from Nocardia sp. and its application to the enzymatic assay of total cholesterol in serum. 1973;19(12):1350-6.

20. Fassati P, Principe LJCC. Measurement of serum triglyceride colorimetrically with an enzyme that produce H2O2. 1982;28(10):2077-80.

21. Evans J, Ellman GJBeBA. The ionization of cysteine. 1959;33(2):574-6.

22. Ohkawa H, Ohishi N, Yagi KJAb. Assay for lipid peroxides in animal tissues by thiobarbituric acid reaction. 1979;95(2):351-8.

23. Ridnour LA, Sim JE, Hayward MA, Wink DA, Martin SM, Buettner GR, et al. A spectrophotometric method for the direct detection and quantitation of nitric oxide, nitrite, and nitrate in cell culture media. 2000;281(2):223-9.

24. Marklund S, Marklund GJEjob. Involvement of the superoxide anion radical in the autoxidation of pyrogallol and a convenient assay for superoxide dismutase. 1974;47(3):469-74.

25. Marrazzo G, Bosco P, La Delia F, Scapagnini G, Di Giacomo C, Malaguarnera M, et al. Neuroprotective effect of silibinin in diabetic mice. 2011;504(3):252-6.

26. Severcan F, Toyran N, Kaptan N, Turan BJT. Fourier transform infrared study of the effect of diabetes on rat liver and heart tissues in the $C \cdot H$ region. 2000;53(1):55-9.

27. Sivakumar S, Sivasubramanian J, Raja BJSAPAM, Spectroscopy B. Aluminium induced structural, metabolic alterations and protective effects of desferrioxamine in the brain tissue of mice: an FTIR study. 2012;99:252-8.

28. Li Y, Wang Z, Furukawa N, Escaron P, Weiszmann J, Lee G, et al. T2384, a novel antidiabetic agent with unique peroxisome proliferator-activated receptor $\gamma$ binding properties. Journal of Biological Chemistry. 2008;283(14):9168-76. 
29. Artis DR, Lin JJ, Zhang C, Wang W, Mehra U, Perreault M, et al. Scaffold-based discovery of indeglitazar, a PPAR pan-active anti-diabetic agent. Proceedings of the National Academy of Sciences. 2009;106(1):262-7.

30. Sugishima M, Omata $Y$, Kakuta $Y$, Sakamoto H, Noguchi M, Fukuyama K. Crystal structure of rat heme oxygenase-1 in complex with heme. FEBS letters. 2000;471(1):61-6.

31. Winkel AF, Engel CK, Margerie D, Kannt A, Szillat H, Glombik H, et al. Characterization of RA839, a noncovalent small molecule binder to Keap1 and selective activator of Nrf2 signaling. Journal of Biological Chemistry. 2015;290(47):28446-55.

32. He MM, Smith AS, Oslob JD, Flanagan WM, Braisted AC, Whitty A, et al. Small-molecule inhibition of TNF- $\alpha$. Science. 2005;310(5750):1022-5.

33. Savvides SN, Karplus PA. Kinetics and crystallographic analysis of human glutathione reductase in complex with a xanthene inhibitor. Journal of Biological Chemistry. 1996;271(14):8101-7.

34. Li H, Jamal J, Delker S, Plaza C, Ji H, Jing $Q$, et al. The mobility of a conserved tyrosine residue controls isoform-dependent enzyme-inhibitor interactions in nitric oxide synthases. Biochemistry. 2014;53(32):5272-9.

35. Gouet P, Jouve H-M, Dideberg O. Crystal Structure ofProteus mirabilisPR Catalase With and Without Bound NADPH. Journal of molecular biology. 1995;249(5):933-54.

36. Buzzetti E, Pinzani M, Tsochatzis EAJM. The multiple-hit pathogenesis of non-alcoholic fatty liver disease (NAFLD). 2016;65(8):1038-48.

37. Wang MQ, Yan AF, Katz RV. Annals of Internal Medicine Researcher Requests for Inappropriate Analysis and Reporting: AU. S. Survey of Consulting Biostatisticians.

38. Flock MR, Green MH, Kris-Etherton PMJAiN. Effects of adiposity on plasma lipid response to reductions in dietary saturated fatty acids and cholesterol. 2011;2(3):261-74.

39. Chang SA, Cha BY, Yoo SJ, Ahn YB, Song KH, Han JH, et al. The effect of cilostazol on glucose tolerance and insulin resistance in a rat model of non-insulin dependent diabetes mellitus. The Korean journal of internal medicine. 2001;16(2):87.

40. Grunwald P. Enzyme Kinetics and Drugs as Enzyme Inhibitors. Pharmaceutical Biocatalysis: Jenny Stanford Publishing; 2019. p. 721-806.

41. Perona JS. Membrane lipid alterations in the metabolic syndrome and the role of dietary oils. Elsevier; 2017.

42. Heeba GH, El-Deen R, Abdel-latif RG, Khalifa MMAJCJoP, Pharmacology. Combined treatments with metformin and phosphodiesterase inhibitors alleviate non-alcoholic fatty liver disease in high-fat diet-fed rats: A comparative study. 2020(ja).

43. Park J-h, Choi B-h, Ku S-K, Kim D-h, Jung K-A, Oh E, et al. Amelioration of high fat diet-induced nephropathy by cilostazol and rosuvastatin. Archives of pharmacal research. 2017;40(3):391-402.

44. Smith BW, Adams LA. Non-alcoholic fatty liver disease. Critical reviews in clinical laboratory sciences. 2011;48(3):97-113.

45. Harris E, Macpherson H, Pipingas AJN. Improved blood biomarkers but no cognitive effects from 16 weeks of multivitamin supplementation in healthy older adults. 2015;7(5):3796-812.

46. Kabil SL. Beneficial effects of cilostazol on liver injury induced by common bile duct ligation in rats: role of SIRT 1 signaling pathway. Clinical and Experimental Pharmacology and Physiology. 2018;45(12):1341-50.

47. Afifi NA, Ramadan A, Erian EY, Saleh DO, Sedik AA, Badawi M, et al. Trigonelline attenuates hepatic complications and molecular alterations in high-fat high-fructose diet-induced insulin resistance in rats. 2017;95(4):427-36.

48. Reddy PVB, Murthy CR, Reddanna PJNI. Fulminant hepatic failure induced oxidative stress in nonsynaptic mitochondria of cerebral cortex in rats. 2004;368(1):15-20. 
49. Nandhini A, Thirunavukkarasu V, Ravichandran M, Anuradha CJSmj. Effect of taurine on biomarkers of oxidative stress in tissues of fructose-fed insulin-resistant rats. 2005;46(2):82.

50. Ragab D, Abdallah DM, El-Abhar HSJPo. Cilostazol renoprotective effect: Modulation of PPAR- $\gamma$, NGAL, KIM-1 and IL-18 underlies its novel effect in a model of ischemia-reperfusion. 2014;9(5):e95313.

51. Bartesaghi $\mathrm{S}$, Radi RJRb. Fundamentals on the biochemistry of peroxynitrite and protein tyrosine nitration. 2018;14:618-25.

52. Abdelsameea AA, Mohamed AM, Amer MG, Attia SMJE, Pathology T. Cilostazol attenuates gentamicin-induced nephrotoxicity in rats. 2016;68(4):247-53.

53. Llacuna L, Bárcena C, Bellido-Martín L, Fernández L, Stefanovic M, Marí M, et al. Growth arrestspecific protein 6 is hepatoprotective against murine ischemia/reperfusion injury. 2010;52(4):1371-9.

54. Diao $Y$, Zhao X-F, Lin J-S, Wang Q-Z, Xu R-AJWJoGW. Protection of the liver against CCI4-induced injury by intramuscular electrotransfer of a kallistatin-encoding plasmid. 2011;17(1):111.

55. Auguet $T$, Vidal F, López-Dupla M, Broch $M$, Gutiérrez $C$, Olona $M$, et al. A study on the TNF- $\alpha$ system in Caucasian Spanish patients with alcoholic liver disease. 2008;92(1-3):91-9.

56. Kawy HSAJEJoP. Cilostazol attenuates cholestatic liver injury and its complications in common bile duct ligated rats. 2015;752:8-17.

57. Lee D-E, Koo H, Sun I-C, Ryu JH, Kim K, Kwon ICJCSR. Multifunctional nanoparticles for multimodal imaging and theragnosis. 2012;41(7):2656-72.

58. da Motta NAV, de Brito FCF. Cilostazol exerts antiplatelet and anti-inflammatory effects through AMPK activation and NF-kB inhibition on hypercholesterolemic rats. Fundamental \& clinical pharmacology. 2016;30(4):327-37.

59. Orhan C, Akdemir F, Sahin N, Tuzcu M, Komorowski J, Hayirli A, et al. Chromium histidinate protects against heat stress by modulating the expression of hepatic nuclear transcription factors in quail. 2012;53(6):828-35.

60. Kim HJ, Moon JH, Kim HM, Yun MR, Jeon BH, Lee B, et al. The hypolipidemic effect of cilostazol can be mediated by regulation of hepatic low-density lipoprotein receptor-related protein 1 (LRP1) expression. 2014;63(1):112-9.

61. Lawal AO, Ellis EMJEt, pharmacology. Nrf2-mediated adaptive response to cadmium-induced toxicity involves protein kinase $C$ delta in human 1321N1 astrocytoma cells. 2011;32(1):54-62.

62. Abuelezz SA, Hendawy NJBP. Insights into the potential antidepressant mechanisms of cilostazol in chronically restraint rats: impact on the Nrf2 pathway. 2018;29(1):28-40.

63. Liyanage $\mathrm{S}$, Abidi $\mathrm{N}$. Fourier transform infrared applications to investigate induced biochemical changes in liver. Applied Spectroscopy Reviews. 2020;55(9-10):840-72.

64. Baquet ZC, Gorski JA, Jones KRJJoN. Early striatal dendrite deficits followed by neuron loss with advanced age in the absence of anterograde cortical brain-derived neurotrophic factor. 2004;24(17):4250-8.

65. Gupta RK, Swain SR, Sahoo J, Chaudhary S, Gupta A. Isolation, characterization and hepatoprotective activity of naturally occurring protopine against simvastatin induced liver toxicity in experimental rodents. Current Bioactive Compounds. 2020;16(5):568-75.

66. Blankenberg FG, Katsikis PD, Storrs RW, Beaulieu C, Spielman D, Chen JY, et al. Quantitative analysis of apoptotic cell death using proton nuclear magnetic resonance spectroscopy. 1997;89(10):3778-86.

67. Park SY, Lee SW, Baek SH, Lee SJ, Lee WS, Rhim BY, et al. Induction of heme oxygenase-1 expression by cilostazol contributes to its anti-inflammatory effects in $\mathbf{J 7 7 4}$ murine macrophages. Immunology letters. 2011;136(2):138-45. 
Table 1: Binding affinity and interaction of cilostazol with the target proteins.

\begin{tabular}{|c|c|c|c|c|c|}
\hline Protein & $\begin{array}{l}\text { PDB } \\
\text { code }\end{array}$ & $\begin{array}{l}\text { Binding energy } \\
\text { (kcal/mol) }\end{array}$ & $\begin{array}{c}\text { Type of interaction, } \\
\text { distance }(\AA)\end{array}$ & $\begin{array}{l}\text { cilostazol atoms involved } \\
\text { in the interaction }\end{array}$ & $\begin{array}{l}\text { Amino acid involved } \\
\text { in the interaction }\end{array}$ \\
\hline \multirow[t]{3}{*}{ PPAR- $\gamma$} & 3K8S & -8.86 & Two H-donor, $3.49 \& 3.66$ & NH & MET 348 \\
\hline & & & H-acceptor, 3.42 & $\mathrm{~N}$ of tetrazole ring & GLN 286 \\
\hline & & & Three pi-H, 3.70, $3.75 \& 3.84$ & Tetrazole ring & CYS 285, HIS 449 \\
\hline PPAR-a & 3ET1 & -9.39 & $\begin{array}{c}\text { Two H-acceptor, } 3.28 \text {, } \\
3.28\end{array}$ & $\mathrm{C}=\mathrm{O}$ & TYR 334 \\
\hline \multirow[t]{2}{*}{ HO-1 } & 1DVE & -8.06 & two H-acceptor, 3.37 & $\mathrm{~N}$ of tetrazole ring & ASP 140 \\
\hline & & & Pi-cation, 3.32 & Tetrazole ring & ARG 136 \\
\hline Nrf-2 & 5CGJ & -8.06 & two H-acceptor, $3.11,2.98$ & $\mathrm{C}=\mathrm{O}$ & ARG 483 \\
\hline \multirow[t]{2}{*}{ TNF- $\alpha$} & $2 \mathrm{AZ5}$ & -6.39 & four H-donor, 3.29 & $\begin{array}{c}\mathrm{NH} \text { and } \mathrm{N} \text { of tetrazole } \\
\text { ring }\end{array}$ & GLY 121 \\
\hline & & & two pi-H, 4.20, 4.25 & Tetrazole ring & LEU 55 \\
\hline \multirow[t]{2}{*}{ GSH } & 1XAN & -6.57 & three H-acceptor, 3.02 & $\mathrm{C}=\mathrm{O}$ & SER 470 \\
\hline & & & three $\mathrm{H}$-acceptor, $3.27,3.36$ & $\mathrm{~N}$ of tetrazole ring & HIS 82 \\
\hline \multirow[t]{6}{*}{ iNOS } & $4 \mathrm{CX} 7$ & -7.60 & $\begin{array}{l}\text { three H-donor , } 3.65,3.64 \text {, } \\
43.65\end{array}$ & $\mathrm{NH}$ & MET 355 \\
\hline & & & three H-donor, 4.21, 4.04, 4.16 & Cyclohexane ring & CYS 200 \\
\hline & & & five $\mathrm{H}$-acceptor, $3.05,2.84,2.89$ & $\mathrm{CO}$ & TYR 491 \\
\hline & & & Two H-acceptor, 3.04, 3.09 & $\mathrm{~N}$ of tetrazole ring & SER 242 \\
\hline & & & Two pi-H, 3.30 & tetrazole ring & GLY 371 \\
\hline & & & Three six pi-H, 4.52 & tetrazole ring & GLY 202 \\
\hline \multirow[t]{2}{*}{ Catalase } & 1TGU & -9.55 & $\begin{array}{c}\text { Three } \mathrm{H} \text {-acceptor, } 2.72,2.85 \text {, } \\
2.88\end{array}$ & $\mathrm{~N}$ of tetrazole ring & ARG 364 \\
\hline & & & Three pi-pi, 3.73, 3.56, 3.77 & Phenyl ring & PHE 160 \\
\hline
\end{tabular}


Table.2. Effect of CILO on Blood haemoglobin concentration, haematocrit and mean corpuscular haemoglobin concentration in NAFLD rats

\begin{tabular}{cccc}
\hline & Hg $(\mathbf{g} / \mathbf{d L})$ & Het $(\%)$ & MCHC (g/ dL) \\
\hline Normal & 15.83 & 55.25 & 28.65 \\
HFD-CH & 15.25 & 51.65 & 29.52 \\
CILO (50 $\mathbf{~ m g / k g ) ~}$ & 15.03 & 51.15 & 29.38 \\
CILO (100 $\mathbf{~ m g / k g ) ~}$ & 15.12 & 51.35 & 29.44
\end{tabular}

NAFLD was induced by daily administration of high fat diet rich in cholesterol for 10 weeks. Oral treatment of HFD-CHinduced- NAFLDwith CILO (50 and $100 \mathrm{mg} / \mathrm{kg}$ ). 24 hours after the last dose of the drugs, Hg, Hctand MCHCconcentrationswere evaluated. Results are expressed as mean \pm SEM ( $n=8)$. *Significant difference from normal control group $p<0.05$. @ Significant difference from NAFLD group. 
Table.3.Effect of CILO on serum AST, ALT, ALP levels and hepatic concentration of TGs and TC in NAFLD rats

\begin{tabular}{|c|c|c|c|c|c|}
\hline Group & $\begin{array}{c}\text { Serum } \\
\text { AST level } \\
(\mathbf{U} / \mathbf{m l}) \\
\end{array}$ & $\begin{array}{c}\text { Serum } \\
\text { ALT level } \\
(\mathrm{U} / \mathrm{ml}) \\
\end{array}$ & $\begin{array}{c}\text { Serum } \\
\text { ALP level } \\
(\mathrm{U} / \mathrm{ml}) \\
\end{array}$ & $\begin{array}{c}\text { Hepatic } \\
\text { TGs } \\
\text { (mg/g tissue) } \\
\end{array}$ & $\begin{array}{c}\text { Hepatic } \\
\text { TC } \\
\text { (mg/g tissue) }\end{array}$ \\
\hline Normal & $20.55 \pm 0.17$ & $35.26 \pm 0.27$ & $17.47 \pm 0.2$ & $80 \pm 0.4$ & $26.46 \pm 0.4$ \\
\hline HFD-CH & $126.5 \pm 0.2^{*}$ & $128.5 \pm 0.2^{*}$ & $108.5 \pm 0.12^{*}$ & $122.5 \pm 0.22^{*}$ & $62.34 \pm 0.4^{*}$ \\
\hline $\begin{array}{c}\text { CILO } \\
(50 \mathrm{mg} / \mathrm{kg})\end{array}$ & $45.07 \pm 0.02^{* @}$ & $65.07 \pm 0.02^{* @}$ & $35.07 \pm 0.022^{* @}$ & $88.63 \pm 0.3^{* @}$ & $36.26 \pm 0.16^{@}$ \\
\hline $\begin{array}{c}\text { CILO } \\
(100 \mathrm{mg} / \mathrm{kg}\end{array}$ & $23.66 \pm 0.36$ *@ & $32.46 \pm 0.64$ *@ & $27.16 \pm 0.23^{* @}$ & $80.63 \pm 0.3^{@}$ & $25.60 \pm 0.44^{@}$ \\
\hline
\end{tabular}

HFD-CH induced- NAFLD with CILO (50 and $100 \mathrm{mg} / \mathrm{kg}) .24$ hours after the last dose of the drugs, serum levels of AST, ALT, ALP and hepatic concentration of $\mathrm{TG}_{\mathrm{S}}$ and TC were evaluated. Results are expressed as mean \pm SEM $(n=8)$. *Significant difference from normal control group $p<0.05$. @ Significant difference from NAFLD group. 
Table.4.Effect of CILO on hepatic oxidative stress biomarkers in NAFLD rats

\begin{tabular}{|c|c|c|c|}
\hline Group & $\begin{array}{c}\text { Hepatic GSH level } \\
\text { ( nmol/g tissue) }\end{array}$ & $\begin{array}{c}\text { Hepatic MDA level } \\
\text { (nmol/g tissue) }\end{array}$ & $\begin{array}{c}\text { Hepatic NO } \\
\text { (nmol/g tissue) }\end{array}$ \\
\hline Normal & $32.55 \pm 0.19$ & $90.66 \pm 0.17$ & $7.86 \pm 0.3$ \\
\hline HFD-CH & $11.56 \pm 0.24^{*}$ & $226.5 \pm 0.2^{*}$ & $45.9 \pm 0.005^{*}$ \\
\hline $\begin{array}{c}\text { CILO } \\
(50 \mathrm{mg} / \mathrm{kg})\end{array}$ & $36.29 \pm 0.27^{* @}$ & $98.07 \pm 0.02^{* @}$ & $14.83 \pm 0.54^{* @}$ \\
\hline $\begin{array}{c}\text { CILO } \\
(100 \mathrm{mg} / \mathrm{kg}\end{array}$ & $33.99 \pm 0.4^{@}$ & $91.07 \pm 0.21^{@}$ & $8.12 \pm 0.16^{@}$ \\
\hline
\end{tabular}

NAFLD was induced by daily administration of HFD-CH for 10 weeks. Oral treatment of HFD-CH induced- NAFLD with CILO (50 and $100 \mathrm{mg} / \mathrm{kg}$ ). 24 hours after the last dose of the drugs, Hepatic levels of GSH, MDA and NO levels were evaluated. Results are expressed as mean \pm SEM $(\mathrm{n}=8)$. *Significant difference from normal control group $\mathrm{p}<0.05$. @ Significant difference from NAFLD group. 
Table.5. Effect of CILO on hepatic levels of pro- inflammatory cytokines in NAFLD rats

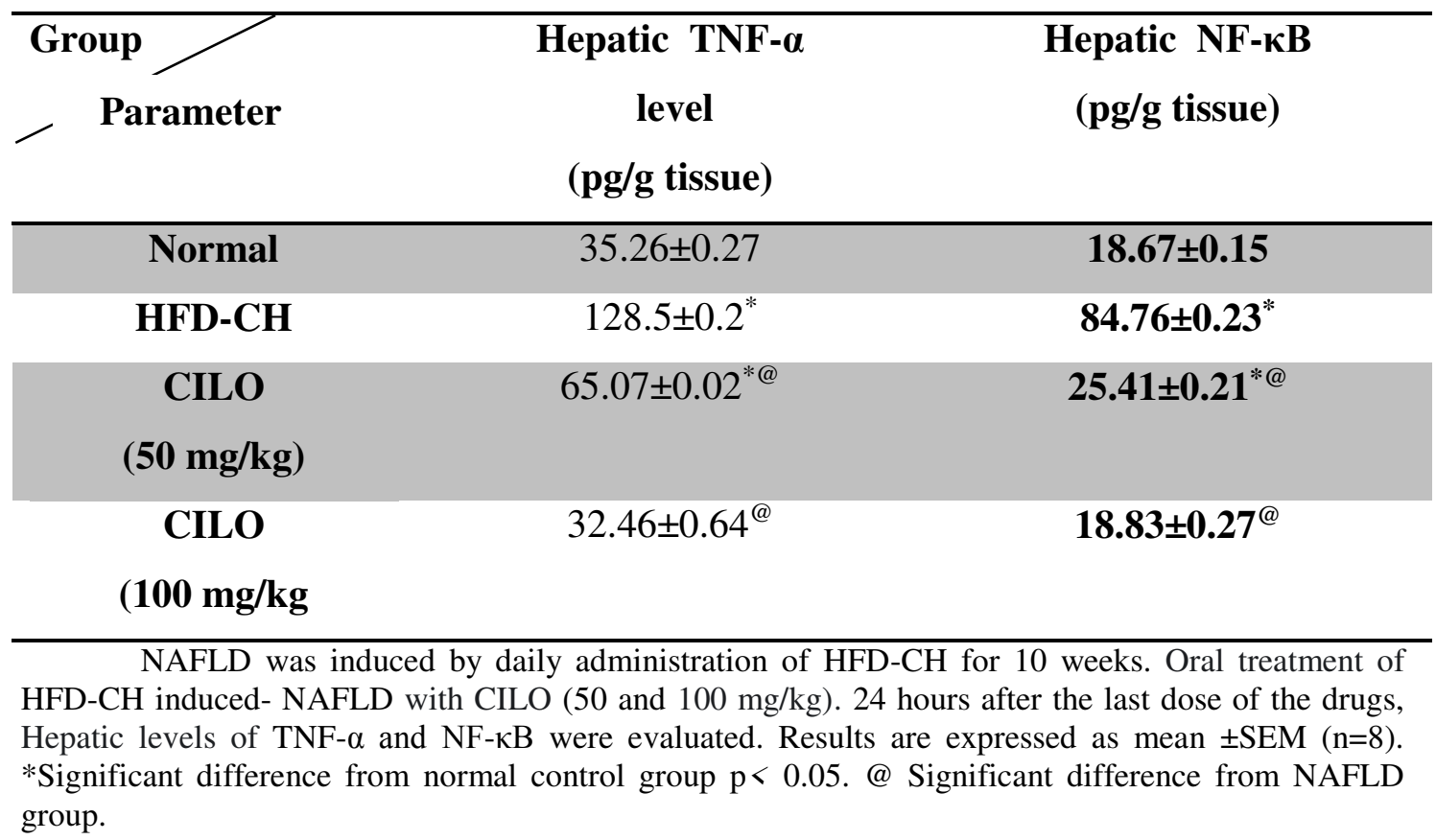



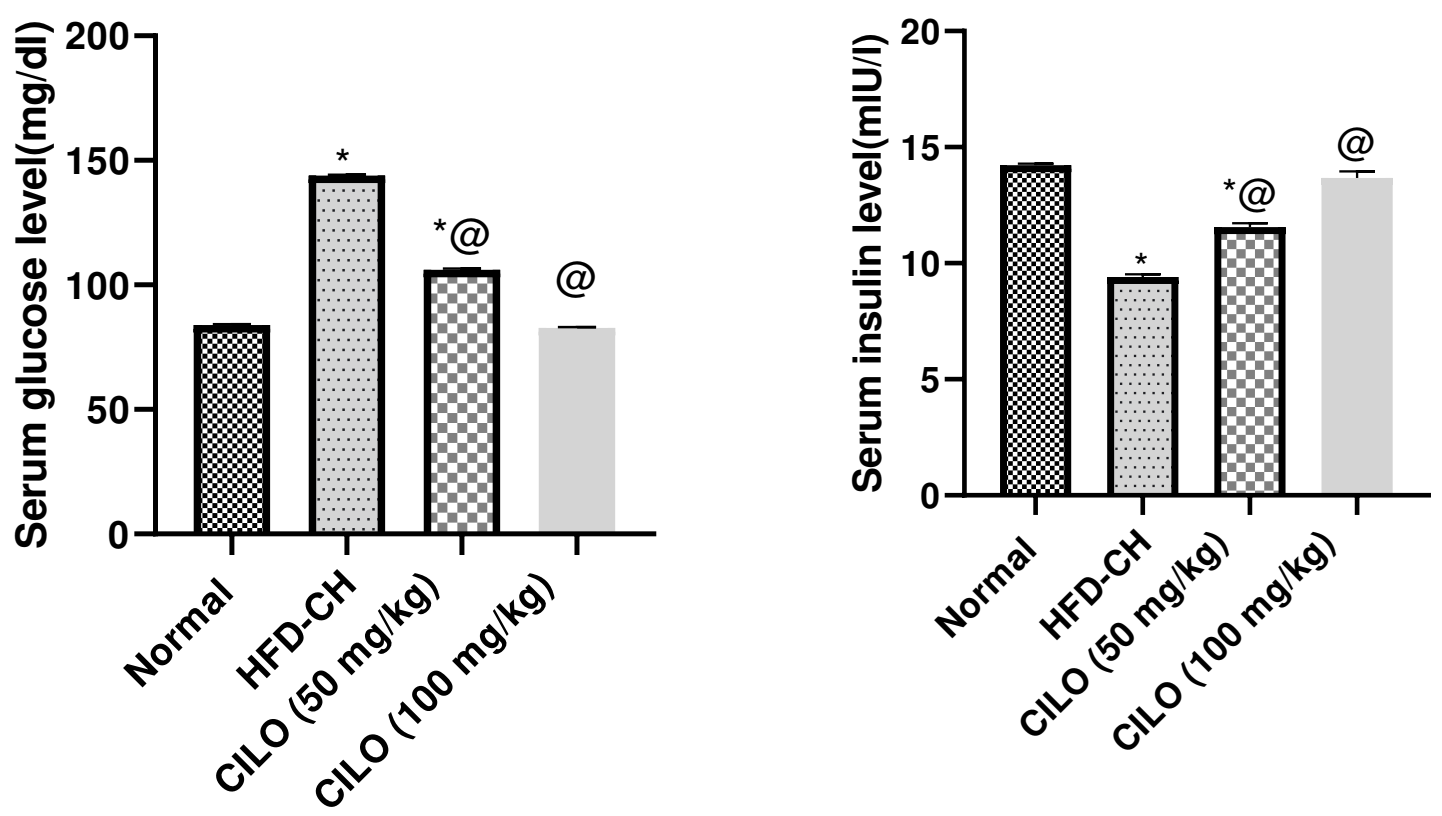

Figure.1. Effect of cilostazol on fasting serum glucose and insulin levels of NAFLD rats

NAFLD was induced by daily administration of high fat diet rich in cholesterol for 10 weeks. Oral treatment of HFD-CH induced- NAFLD with CILO (50 and $100 \mathrm{mg} / \mathrm{kg}) .24$ hours after the last dose of the drugs, hepatic Nrf-2 expression and HO-1 levels fasting serum glucose and insulin levels were evaluated. Results are expressed as mean \pm SEM $(n=8)$. *Significant difference from normal control group $\mathrm{p}<0.05$. @ Significant difference from NAFLD group. 

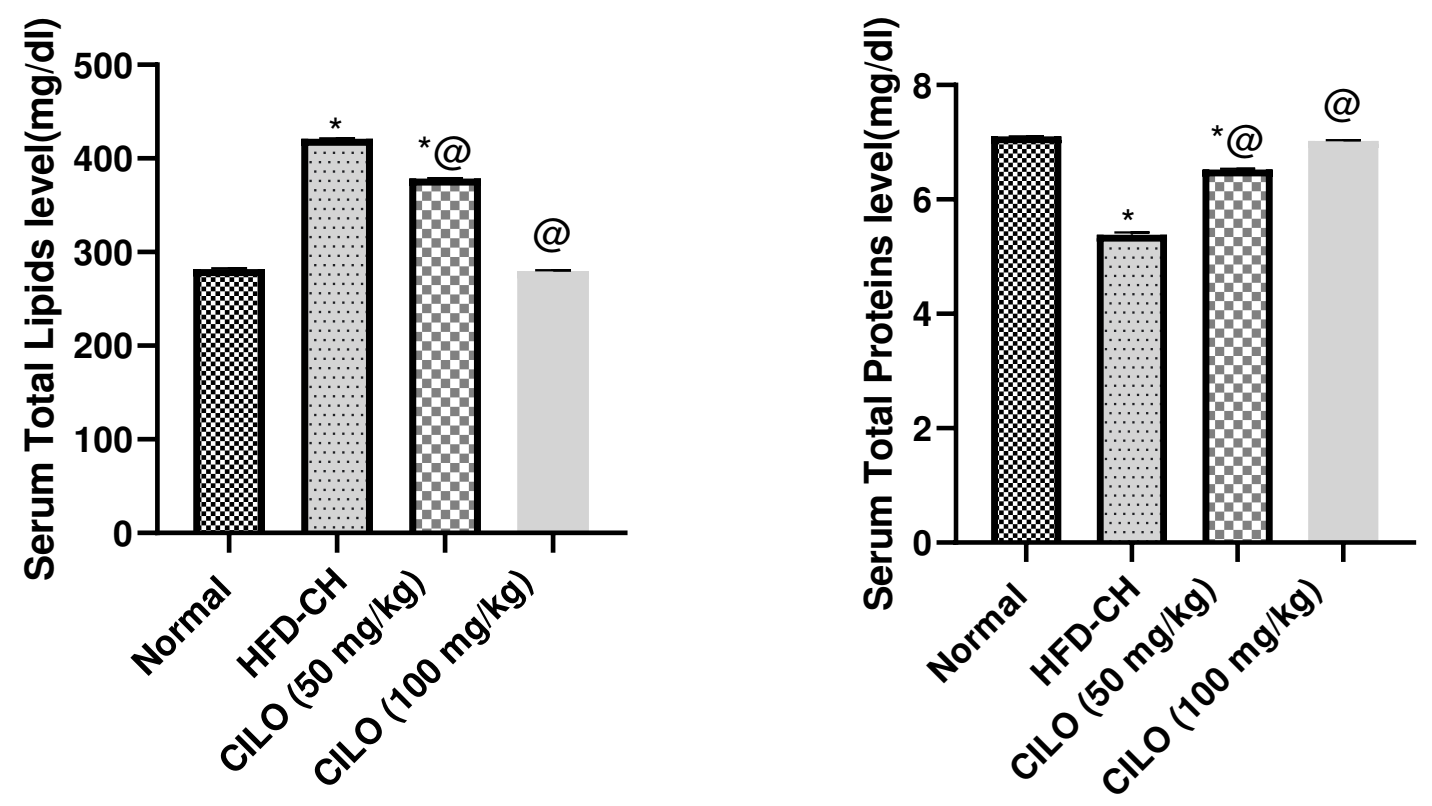

Figure.2. Effect of cilostazol on fasting serum total lipids and total protein levels of

\section{NAFLD rats}

NAFLD was induced by daily administration of high fat diet rich in cholesterol for 10 weeks. Oral treatment of HFD-CH induced- NAFLD with CILO (50 and $100 \mathrm{mg} / \mathrm{kg}$ ). 24 hours after the last dose of the drugs, fasting serum total lipids and total protein levels were evaluated. Results are expressed as mean \pm SEM $(n=8)$. *Significant difference from normal control group $p<0.05$. @ Significant difference from NAFLD group. 

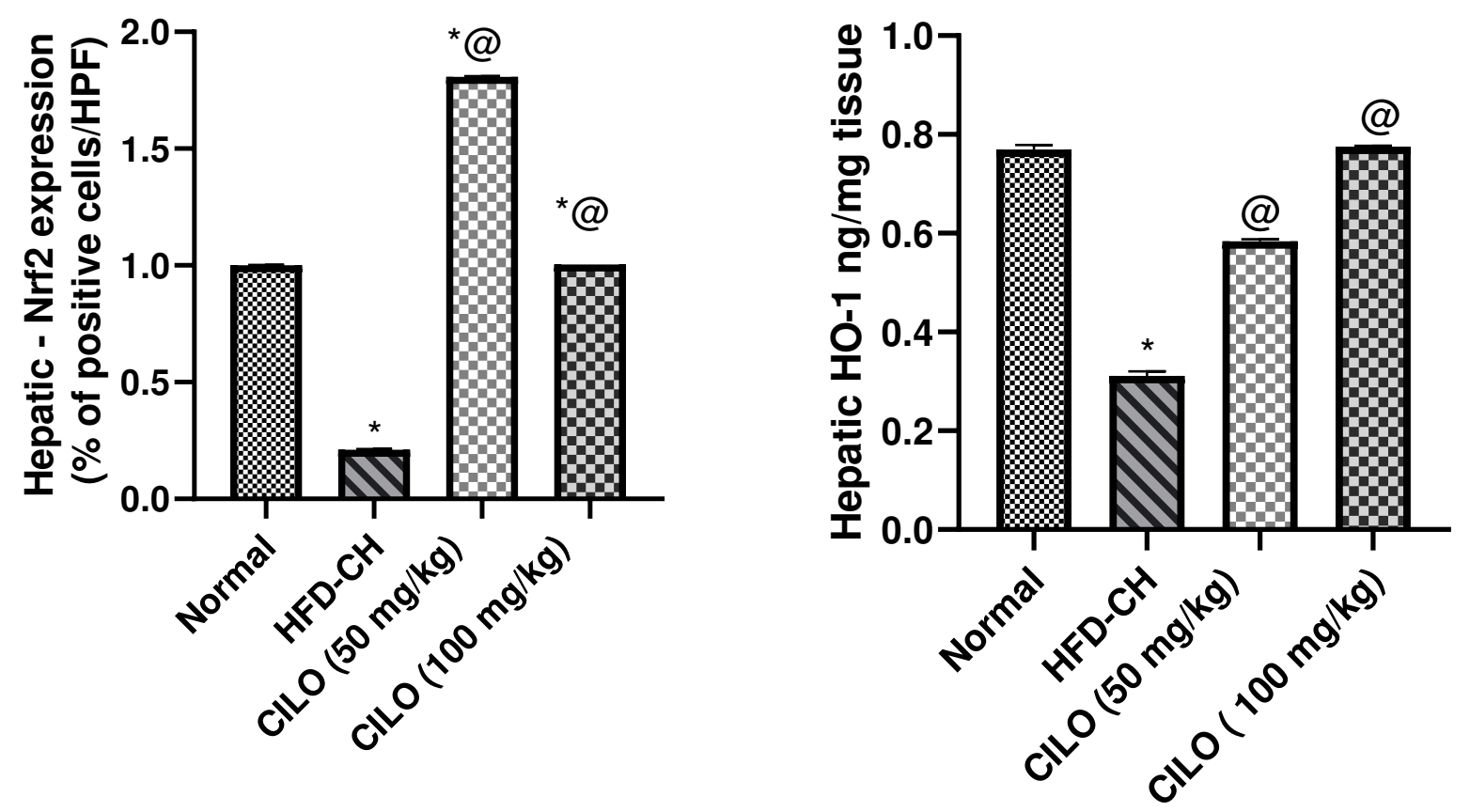

Figure.3. Effect of cilostazol on Nrf-2 expression and HO-1 levels in hepatic tissue of NAFLD rats

NAFLD was induced by daily administration of high fat diet rich in cholesterol for 10 weeks. Oral treatment of HFD-CH induced- NAFLD with CILO (50 and $100 \mathrm{mg} / \mathrm{kg}$ ). 24 hours after the last dose of the drugs, hepatic Nrf-2 expression and HO-1 levels were evaluated. Results are expressed as mean \pm SEM $(n=8)$. *Significant difference from normal control group $\mathrm{p}<0.05$. @ Significant difference from NAFLD group. 


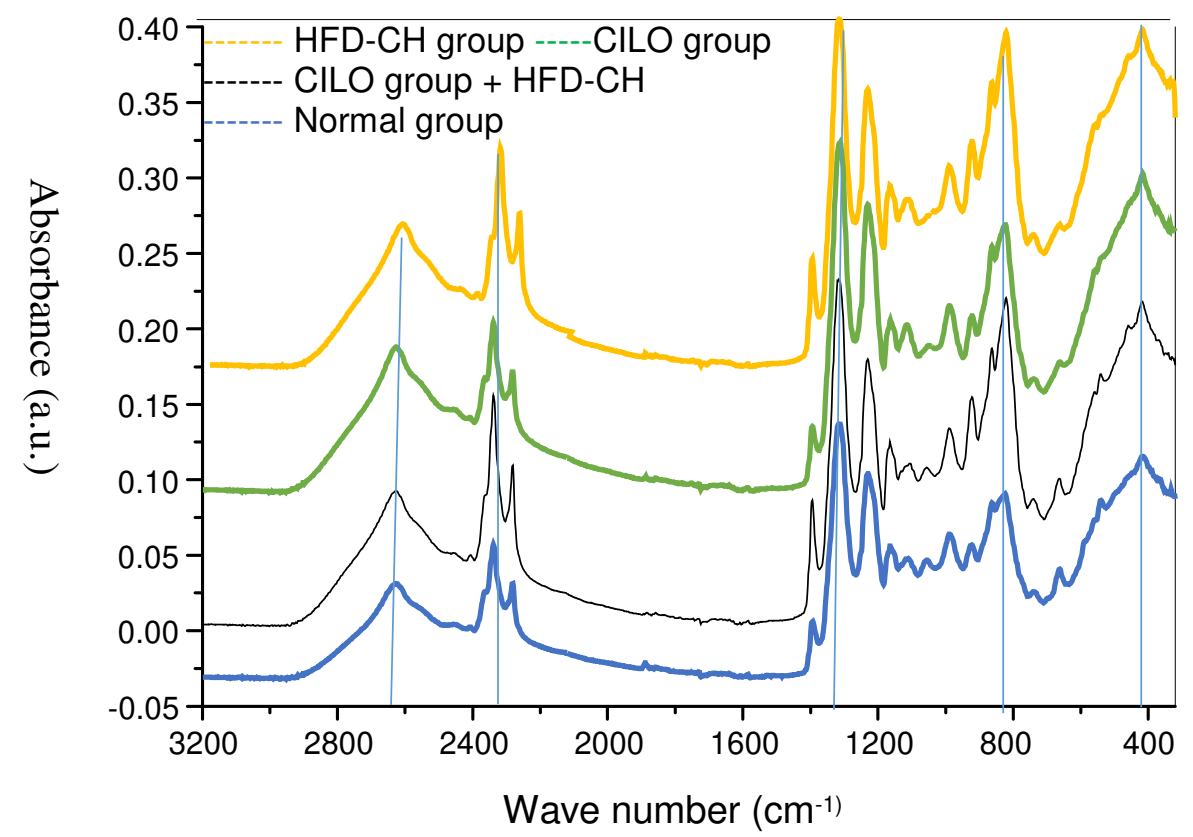

Figure.4. Effect of cilostazol on wave number alterations in hepatic tissue of NAFLD rats

NAFLD was induced by daily administration of high fat diet rich in cholesterol for 10 weeks. Oral treatment of HFD-CH induced- NAFLD with CILO (50 and $100 \mathrm{mg} / \mathrm{kg}$ ). 24 hours after the last dose of the drugs, wave number alterations were evaluated. Results are expressed as mean \pm SEM $(n=8)$. *Significant difference from normal control group $\mathrm{p}<0.05$. @ Significant difference from NAFLD group. 


\begin{tabular}{|c|c|}
\hline 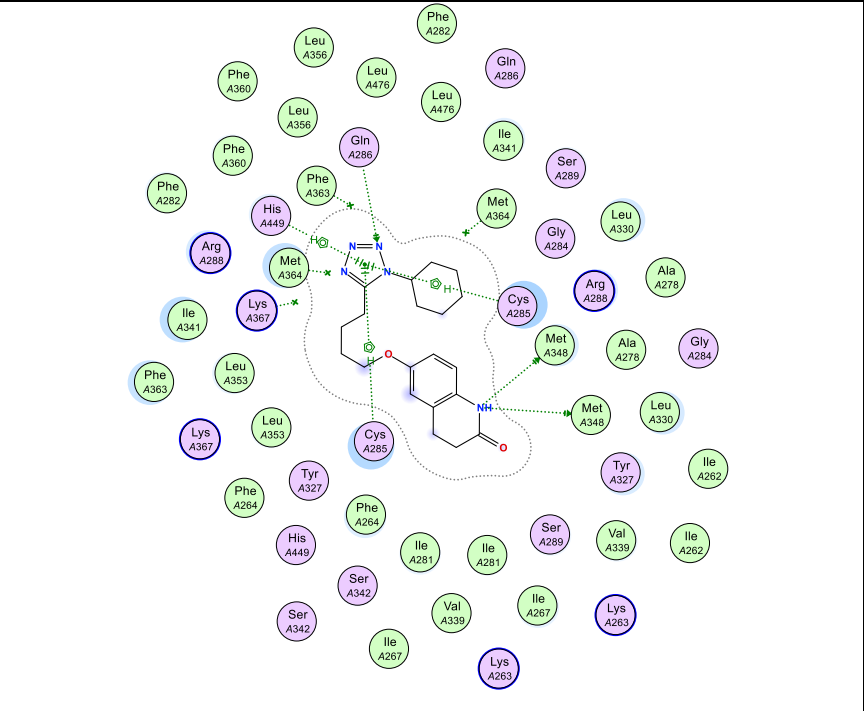 & 0 \\
\hline $\begin{array}{l}\text { Figure 5a: } 2 \mathrm{D} \text { conformations of the cilostazol in the active } \\
\text { site of the PPAR } \gamma \text { receptor (PDB ID: } 3 \mathrm{~K} 8 \mathrm{~S} \text { ). }\end{array}$ & $\begin{array}{l}\text { Figure 5b: 3D conformations of the cilostazol (yellow) } \\
\text { in the active site of the PPAR } \gamma \text { receptor (PDB ID: } \\
\text { 3K8S). }\end{array}$ \\
\hline 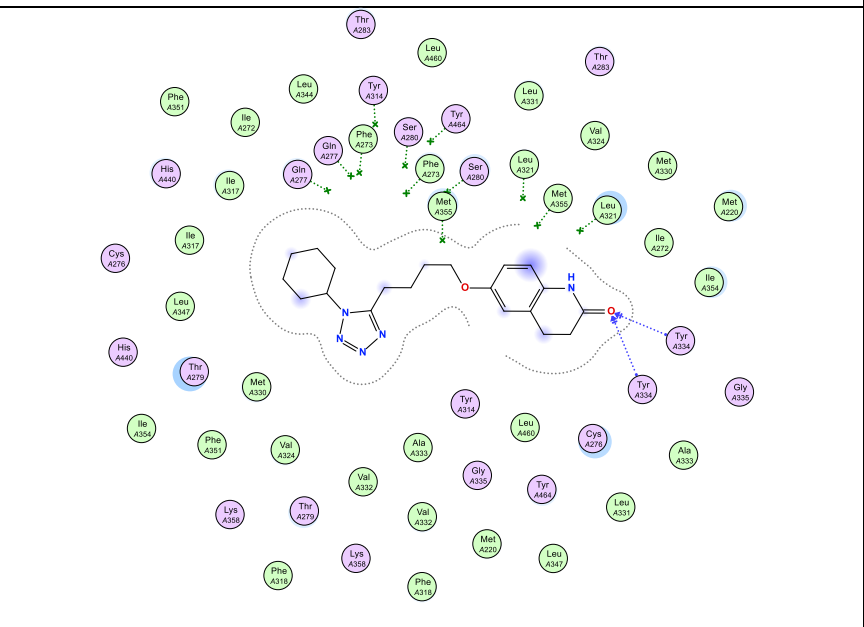 & 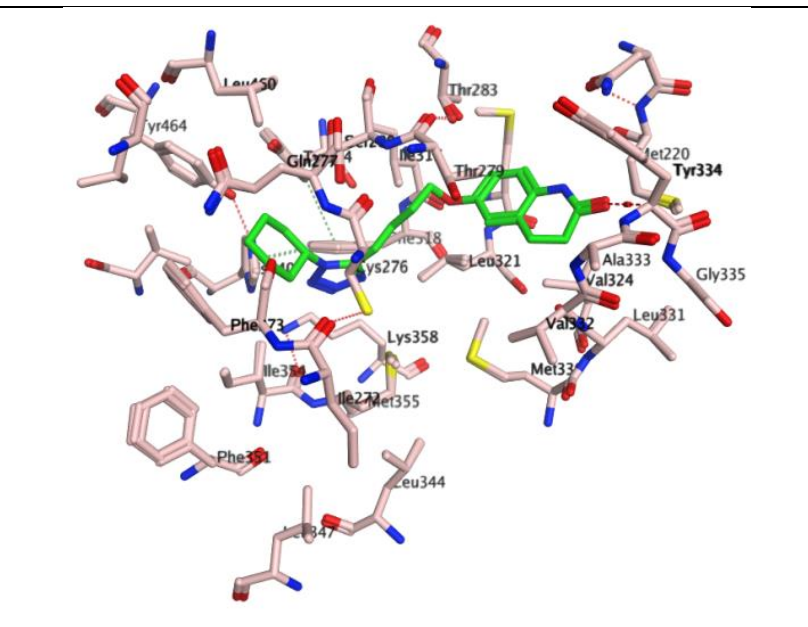 \\
\hline $\begin{array}{l}\text { Figure 6a: } 2 \mathrm{D} \text { conformations of the cilostazol in the active } \\
\text { site of the PPAR } \alpha \text { receptor (PDB ID: } 3 \mathrm{ET} 1 \text { ). }\end{array}$ & $\begin{array}{l}\text { Figure 6b: 3D conformations of the cilostazol in the } \\
\text { (green) active site of the PPAR } \alpha \text { receptor (PDB ID: } \\
\text { 3ET1). }\end{array}$ \\
\hline
\end{tabular}




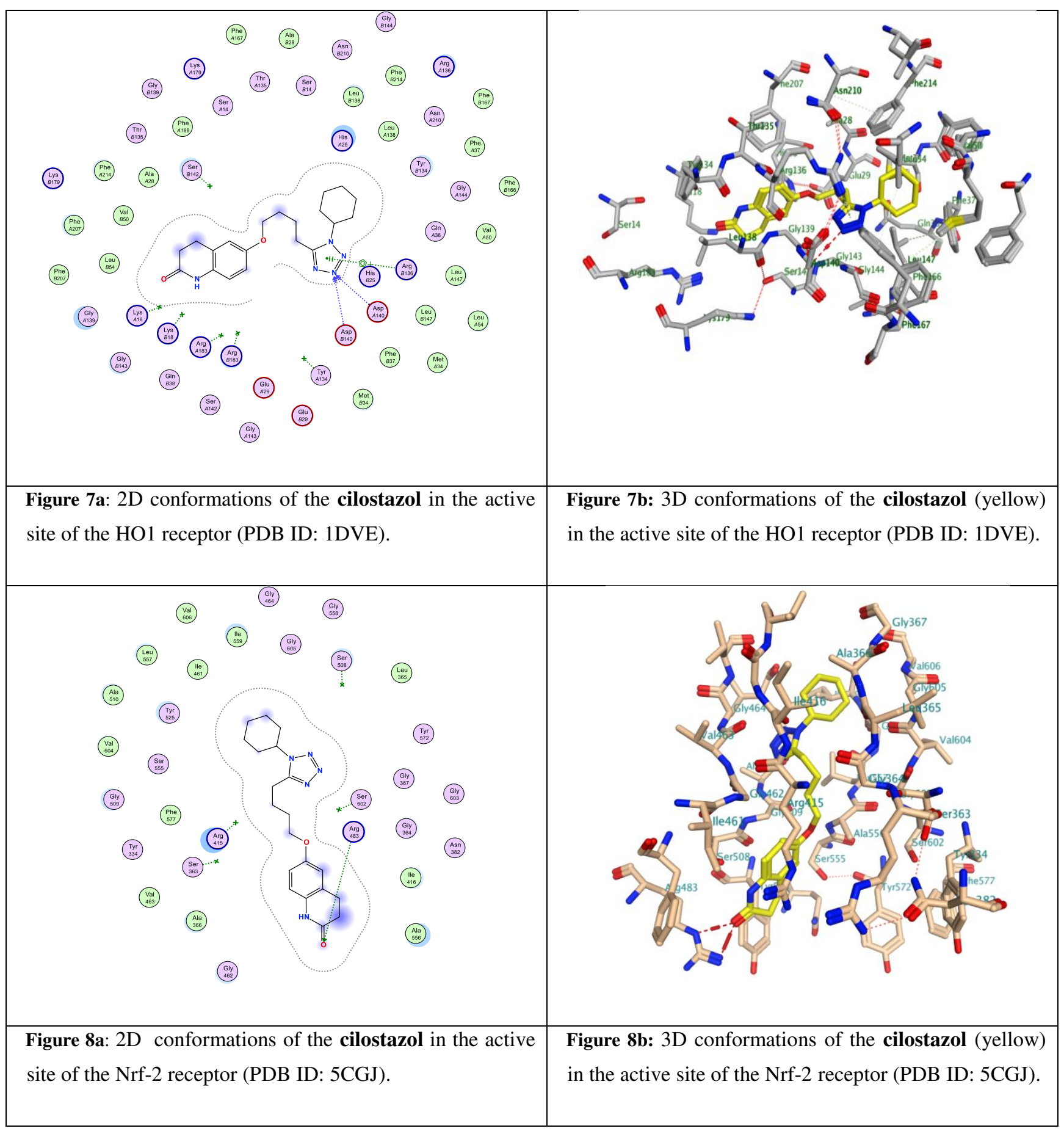




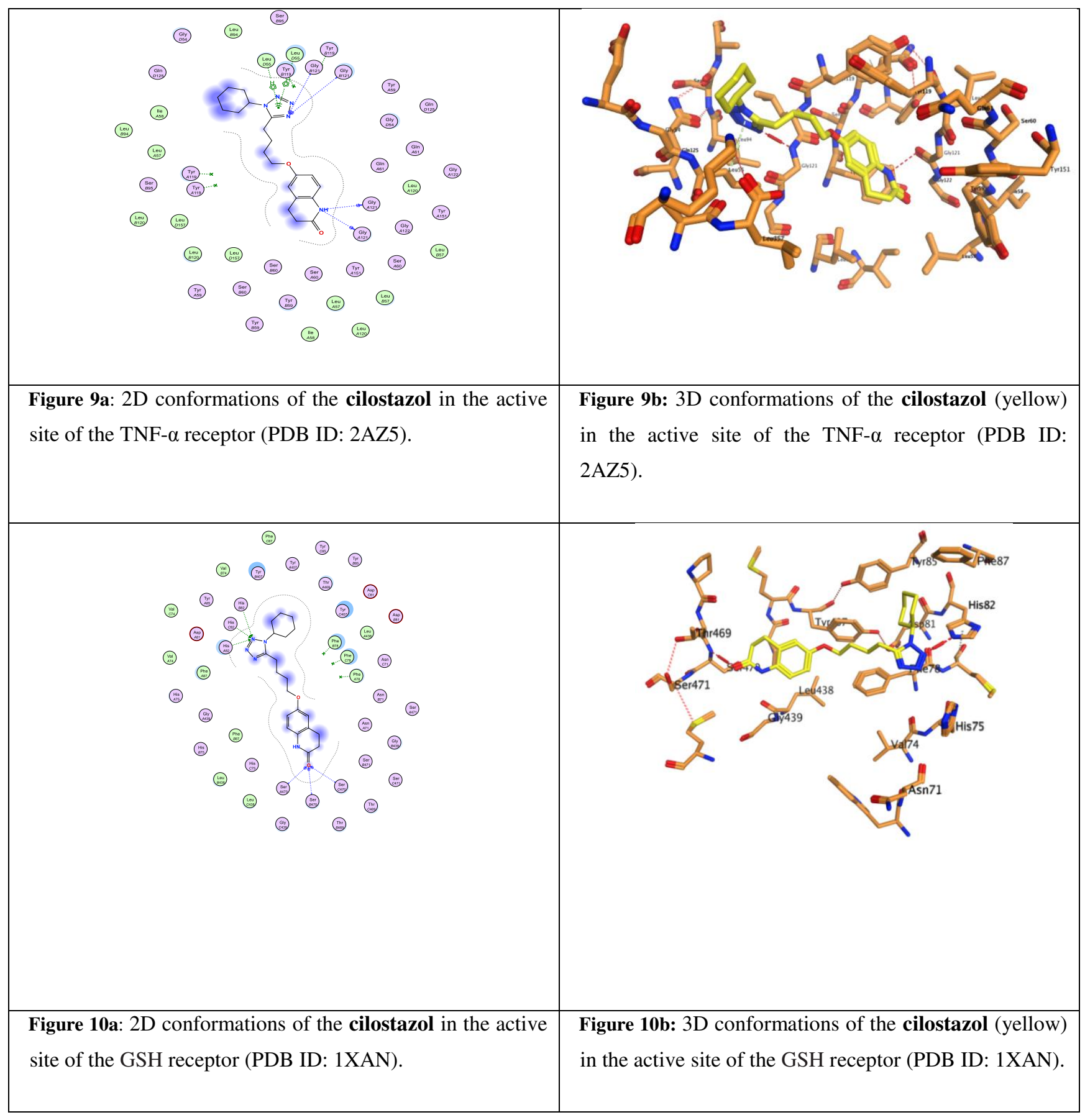




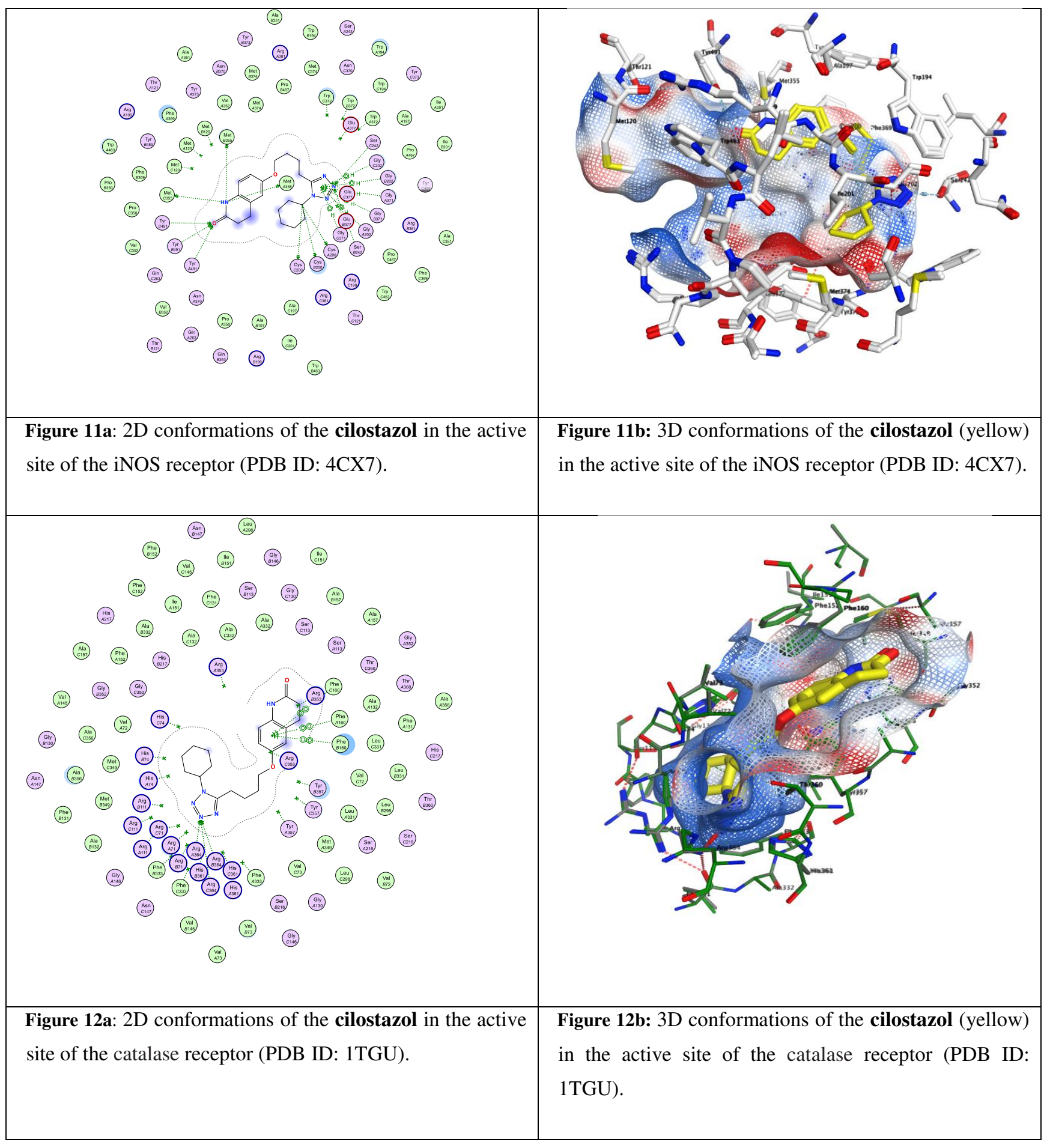




\section{Cover letter}

February 9, 2022

Editorial Department of European Journal of Pharmacology

Dear Editor of European Journal of Pharmacology

I am submitting a manuscript for consideration of publication in European Journal of Pharmacology. The manuscript is entitled "Modulatory Effects of Cilostazol; an Nrf2/HO-1 activator against NAFLD in Rats Confirmed by Molecular Docking and FTIR Studies".

It has not been published elsewhere and that it has not been submitted simultaneously for publication elsewhere.

NAFLD is a hepato-metabolic syndrome that is usually implicated in sever clinical and pathological disorders and is considered the major precipitating factors for insulin resistance, diabetes mellitus and cardiovascular diseases. NAFLD is asymptomatic hepatic manifestation that can progress to nonalcoholic steatohepatitis (NASH), hepatic fibrosis, cirrhosis, and hepatic cancer. Our study revealed the modulatory effect of cilostazol against nonalcoholic fatty liver disease induced by high fat diet rich may be attributed to its anti-hyperlipedemic activity, activation of $\mathrm{Nrf} 2 / \mathrm{HO}-1$ pathway, amelioration of oxidative stress, reducing the expression of pro-inflammatory cytokines. Thus, CILO may be a promising supplement to be used for patients with NAFLD in the future.

Thank you very much for your consideration.

Yours Sincerely,

Ahmed A.Sedik

$1^{*}$ Department of Pharmacology, Medical Research and Clinical Studies Institute, National Research Center, National Research Centre, Dokki, 12622, Cairo, Egypt

Corresponding author: Ahmed A. Sedik

E-mail: aa.sedik@gmail.com

Tel: +201271667899 


\section{Author declaration}

[Instructions: Please check all applicable boxes and provide additional information as requested.]

\section{$\underline{\text { 1. Conflict of Interest }}$}

Potential conflict of interest exists:

We wish to draw the attention of the Editor to the following facts, which may be considered as potential conflicts of interest and to significant financial contributions to this work:

The nature of potential conflict of interest is described below:

\section{$\underline{\sqrt{ } \sqrt{ } \text { No conflict of interest exists. }}$}

We wish to confirm that there are no known conflicts of interest associated with this publication and there has been no significant financial support for this work that could have influenced its outcome.

\section{Funding}

$\square$ Funding was received for this work.

All of the sources of funding for the work described in this publication are acknowledged below:

[List funding sources and their role in study design, data analysis, and result interpretation]

\section{$\sqrt{\sqrt{ } \text { No funding was received for this work. }}$}

\section{Intellectual Property}

$\sqrt{ } \sqrt{ }$ We confirm that we have given due consideration to the protection of intellectual property associated with this work and that there are no impediments to publication, including the timing of publication, with respect to intellectual property. In so doing we confirm that we have followed the regulations of our institutions concerning intellectual property.

\section{Research Ethics}

$\sqrt{ } \sqrt{ }$ We further confirm that any aspect of the work covered in this manuscript that has involved human patients has been conducted with the ethical approval of all relevant bodies and that such approvals are acknowledged within the manuscript.

$\square$ IRB approval was obtained (required for studies and series of 3 or more cases) 
$\square$ Written consent to publish potentially identifying information, such as details or the case and photographs, was obtained from the patient(s) or their legal guardian(s).

\section{$\underline{\text { 5. Authorship }}$}

The International Committee of Medical Journal Editors (ICMJE) recommends that authorship be based on the following four criteria:

1. Substantial contributions to the conception or design of the work; or the acquisition, analysis, or interpretation of data for the work; AND

2. Drafting the work or revising it critically for important intellectual content; AND

3. Final approval of the version to be published; AND

4. Agreement to be accountable for all aspects of the work in ensuring that questions related to the accuracy or integrity of any part of the work are appropriately investigated and resolved.

All those designated as authors should meet all four criteria for authorship, and all who meet the four criteria should be identified as authors. For more information on authorship, please see http://www.icmje.org/recommendations/browse/roles-andresponsibilities/defining-the-role-of-authors-and-contributors.html\#two.

$\underline{\sqrt{ }}$ All listed authors meet the ICMJE criteria. We attest that all authors contributed significantly to the creation of this manuscript, each having fulfilled criteria as established by the ICMJE.

$\square$ One or more listed authors do(es) not meet the ICMJE criteria.

We believe these individuals should be listed as authors because:

[Please elaborate below]

$\sqrt{ } \sqrt{ }$ We confirm that the manuscript has been read and approved by all named authors.

$\sqrt{ } \sqrt{ }$ We confirm that the order of authors listed in the manuscript has been approved by all named authors.

\section{Contact with the Editorial Office}

The Corresponding Author declared on the title page of the manuscript is:

\section{[Ahmed A.Sedik}

$\square$ This author submitted this manuscript using his/her account in EVISE. 
$\sqrt{ } \sqrt{ }$ We understand that this Corresponding Author is the sole contact for the Editorial process (including EVISE and direct communications with the office). $\mathrm{He} / \mathrm{she}$ is responsible for communicating with the other authors about progress, submissions of revisions and final approval of proofs.

$\sqrt{ }$ We confirm that the email address shown below is accessible by the Corresponding Author, is the address to which Corresponding Author's EVISE account is linked, and has been configured to accept email from the editorial office of Pharmacological Research:

[aa.sedik@gmail.com]

$\square$ Someone other than the Corresponding Author declared above submitted this manuscript from his/her account in EVISE:

[Insert name below]

$\square$ We understand that this author is the sole contact for the Editorial process (including EVISE and direct communications with the office). He/she is responsible for communicating with the other authors, including the Corresponding Author, about progress, submissions of revisions and final approval of proofs.

We the undersigned agree with all of the above.
Author's name (Fist, Last)
Signature
Date

1. Ahmed A.Sedik

Ahmed A.Sedik

$9-2-2022$

2. Asmaa A. Amer

Asmaa_A. Amer

9-2-2022 